\title{
1 Host Cell Proteases Drive Early or Late SARS-CoV-2 Penetration
}

2 Jana Koch ${ }^{1,2,3, \#}$, Zina M Uckeley ${ }^{1,2,3, \#}$, Patricio Doldan ${ }^{1,3}$, Megan Stanifer $^{1,5, \star}$, Steeve Boulant ${ }^{1,3,4, *}$,

3 Pierre-Yves Lozach ${ }^{1,2,3,6, *}$

$4{ }^{1}$ Center for Integrative Infectious Diseases Research (CIID), University Hospital Heidelberg,

569120 Heidelberg, Germany; ${ }^{2}$ CellNetworks - Cluster of Excellence, 69120 Heidelberg, Germany;

$6{ }^{3}$ Department of Infectious Diseases, Virology, University Hospital Heidelberg, 69120 Heidelberg,

7 Germany; ${ }^{4}$ German Cancer Center (DKFZ), 69120 Heidelberg, Germany; ${ }^{5}$ Department of

8 Infectious Diseases, Molecular Virology, University Hospital Heidelberg, 69120 Heidelberg,

9 Germany; ${ }^{6}$ Univ. Lyon, INRAE, EPHE, IVPC, 69007 Lyon, France

10 "these authors contributed equally

$11{ }^{*}$ Correspondence: pierre-yves.lozach@med.uni-heidelberg.de; m.stanifer@dkfz-heidelberg.de;

12 s.boulant@dkfz-heidelberg.de

13 Running title: SARS-CoV-2 entry

\section{Keywords}

15 Coronavirus; COVID-19; protease; SARS-CoV-2; virus entry

\section{Author contributions}

17 J.K., Z.M.U., and P.Y.L. designed research; J.K., Z.M.U., P.D., and M.S. performed research; J.K.,

18 Z.M.U., M.S., S.B., and P.Y.L. analyzed data; P.Y.L. wrote the original draft; and J.K., Z.M.U.,

19 M.S., S.B., and P.Y.L. reviewed and edited the paper.

20 The authors declare no conflict of interest. 


\section{Abstract}

22 SARS-CoV-2 is a newly emerged coronavirus (CoV) that spread through human populations

23 worldwide in early 2020. CoVs rely on host cell proteases for activation and infection. The trypsin-

24 like protease TMPRSS2 at the cell surface, cathepsin L in endolysosomes, and furin in the Golgi

25 have all been implicated in the SARS-CoV-2 proteolytic processing. Whether SARS-CoV-2 depends on endocytosis internalization and vacuolar acidification for infectious entry remains unclear. Here, we examined the dynamics of SARS-CoV-2 activation during the cell entry process in tissue culture. Using four cell lines representative of lung, colon, and kidney epithelial tissues, we found that TMPRSS2 determines the SARS-CoV-2 entry pathways. In TMPRSS2-positive cells, infection was sensitive to aprotinin, a TMPRSS2 inhibitor, but not to SB412515, a drug that impairs cathepsin L. Infectious penetration was marginally dependent on endosomal acidification, and the virus passed the protease-sensitive step within $10 \mathrm{~min}$. In a marked contrast, in cathepsin L-activated penetration occurred within 40-60 min after internalization and required intact endolysosomal functions. Importantly, pre-activation of the virus allowed it to bypass the need for endosomal acidification for viral fusion and productive entry. Overall, our results indicate that SARS-CoV-2 shares with other CoVs a strategy of differential use of host cell proteases for activation and infectious penetration. This study also highlights the importance of TMPRSS2 in dictating the entry pathway used by SARS-CoV-2.

\section{Significance}

41 Preventing SARS-CoV-2 spread requires approaches affecting early virus-host cell interactions

42 before the virus enters and infects target cells. Host cell proteases are critical for coronavirus 43 activation and infectious entry. Here, we reconcile apparent contradictory observations from 44 recent reports on endosomal acidification and the role of furin, TMPRSS2, and cathepsin L in the 
46 types, we demonstrated that SARS-CoV-2 developed the ability to use different entry pathways,

47 depending on the proteases expressed by the target cell. Our results have strong implications for

48 future research on the apparent broad tropism of the virus in vivo. This study also provides a

49 handle to develop novel antiviral strategies aiming to block virus entry, as illustrated with the

50 several drugs that we identified to prevent SARS-CoV-2 infection, some with low $\mathrm{IC}_{50}$. 


\section{Introduction}

52 The Coronaviridae is a large viral family of several hundred members, which constitutes along

53 with Arteriviridae and Roniviridae the order Nidovirales (1). To date, four coronaviruses (CoVs)

54 have been identified as the leading cause for common colds in humans (2). Three other CoVs,

55 causing severe respiratory diseases, have emerged into the human population as a result of

56 spillover events from wildlife during the last two decades (3). Severe acute respiratory syndrome

57 (SARS)-CoV and Middle East respiratory syndrome (MERS)-CoV were first isolated in China in

2002 and Saudi Arabia in 2011, respectively (3). The most recent, SARS-CoV-2, is responsible

for CoV induced disease (COVID-19) and turned into a pandemic in early 2020. As of December

22, 2020, more than 77 million human cases have been reported with at least 1.7 million deaths.

As other CoVs, SARS-CoV-2 particles are enveloped, roughly spherical, with a diameter

between 90 and $110 \mathrm{~nm}(4,5)$. The viral genome consists of one single-stranded positive-sense

RNA segment that replicates in the cytosol and encodes four structural proteins. Three

transmembrane proteins are embedded in the viral envelope and are exposed at the virion

surface, namely the large glycoprotein $\mathrm{S}$, the membrane protein $\mathrm{M}$, and the envelope protein $\mathrm{E}$ (3). The nucleoprotein NP binds to the genomic RNA to form nucleocapsid structures inside the

viral particles. In the viral envelope, glycoprotein $S$ forms spike-like projections up to $35 \mathrm{~nm}$ in length, responsible for virus attachment to host cells and penetration by membrane fusion (6).

Although SARS-CoV-2 has been the subject of intense research since the beginning of 2020, our current understanding of cell entry remains essentially derived from studies on SARS-

71 CoV and other CoVs (3). SARS-CoV-2 has been shown to rely on ACE2 (7), heparan sulfates (8),

72 and neuropilin-1 (9) at the cell surface for infection. Inhibitor studies support the possibility that the

73 virus enters the endosomal vesicles and relies on vacuolar acidification for the infectious entry

74 process $(7,10,11)$. As with many other CoVs, there is intense debate as to whether SARS-CoV-

752 enters the host cells from the plasma membrane or from intracellular compartments. 
To gain access into the cytosol, enveloped viruses must fuse their envelope with the cell membrane. Several classes of viral fusion proteins are known to mediate this process, each with their own molecular specificities [reviewed in (12)]. Structural studies categorized the SARS-CoV2 protein $S$ as a Class-I viral fusion protein, within the same group as other corona-, human immunodeficiency, and influenza (IAV) viruses (13-15). Cryo-electron microscopy showed that the

81 S protein forms homotrimers at the surface of SARS-CoV-2 particles, in which the viral fusion 82 subunits are buried $(13,14)$. The activation of the Class-I viral fusion proteins usually involves 83 proteolytic processing, and membrane fusion is triggered by interactions with cell receptors and sometimes endosomal acidification. Activation and priming are irreversible steps, and the Class-I viral fusion proteins act only once (12). In the case of SARS-CoV-2, endosomal acidification appears to be non-essential to induce the spike-mediated fusion of the host membrane with the viral envelope (16). Yet why SARS-CoV-2 infection is sensitive to perturbants of endosomal acidification remains unclear.

Several proteases have been proposed to prime and activate the S protein (17), a step prior virus fusion and infection. Furin is a calcium-dependent serine endoprotease widely expressed in tissues. It has been proposed to cleave the S protein at the site S1/S2 (17-19), most likely when

92 the viral progeny exits the infected cells. The cleavage results in two subunits, S1 and S2. S1 contains a receptor binding domain, and $\mathrm{S} 2$ the membrane fusion effector. An additional proteolytic cleavage in the S2 subunit occurs at the site S2' during virus entry to trigger the fusion of the viral envelope with the host cell membrane. The transmembrane serine protease 2 (TMPRSS2), a cell surface trypsin-like protease (20), and cathepsin L, an endolysosomal cysteine

97 protease (21), have both been proposed to be involved in the cleavage at the S2' site $(5,7,17$, $22,23)$. Still, the timing and dynamics of proteolytic cleavages and their potential role in SARS-

99 CoV-2 activation, fusion, and entry remain unclear. 
102 TMPRSS2, and cathepsin L most likely differentially influences the cell entry mechanisms of

103 SARS-CoV-2 in a specific manner. In the present study, we developed sensitive, quantitative

104 assays to analyze the SARS-CoV-2 entry process in different epithelial cell types. Using these

105 assays, we determined SARS-CoV-2 dependence on low pH, proteolytic processing, proteases-

106 and endosomal acidification-requiring dynamics, endocytosis, and protease-activated membrane

107 fusion. Our work established that SARS-CoV-2 shares with MERS-CoV and other CoVs the ability

108 to make a differential use of host cell proteases to enter and infect target cells. 


\section{Results}

\section{Characterization of SARS-CoV-2 Life Cycle in Caco-2 and Vero Cells}

111 Many epithelial cell types have been reported to support productive SARS-CoV-2 infection (7), 112 and both the TMPRSS2 and cathepsin L proteases have been implicated in the proteolytic 113 processing of the viral S protein $(5,7,17,22,23)$. We selected four epithelial cell lines that are 114 known to support SARS-CoV-2 infection, i.e., Calu-3, Caco-2, A549, and Vero cells (7). A549 are 115 intrinsically poorly infectable by SARS-CoV-2 due to the absence of the SARS-CoV-2 receptor ACE2 (7). As such, we used A549 cells stably overexpressing ACE2 (A549*). When cell lysates were subjected to SDS-PAGE and western blotting, we found that TMPRSS2 was effectively expressed in Calu-3 cells and to a lower extent in Caco-2 cells (Fig. 1A), corroborating results from others (24). Regardless of the presence of TMPRSS2, cathepsin L (from 25 to $31 \mathrm{kDa}$ ) and its inactive form, i.e., procathepsin $L(35$ to $41 \mathrm{kDa}$ ), were present in all the cell lines (Fig. 1B). However, the conversion of procathepsin $L$ to cathepsin $L$ appeared significantly higher in Vero cells than in the three other cell lines.

To address how the presence or absence of TMPRSS2 influences the SARS-CoV-2 infectious penetration, and how the endosomal acidification contributes to the process, we aimed to compare cell lines expressing or not this protease. To this end, we first defined the timing for a 126 single round of infection using our cell lines. Calu-3 and Caco-2 served as TMPRSS2-positive 127 (TMPRSS2+) cells, and A549* and Vero as non-expressing cells. The susceptibility of Caco-2 and 128 Vero cells to SARS-CoV-2 at multiplicities of infection (MOIs) of 0.1 and 0.5 , respectively, was 129 assessed by fluorescence microscopy after immunostaining with a mouse monoclonal antibody $130(\mathrm{mAb})$ against the intracellular viral nucleoprotein NP (Fig. 1C). Results show that 10\% of Caco-2 131 cells were positive for NP at 8 hours post-infection (hpi). Similarly, 35\% of Vero cells were found 132 infected at $8 \mathrm{hpi}$ (Fig. 1C).

To quantify infection more accurately, we then performed flow cytometry analysis of Caco-

1342 and Vero cells infected with different MOls of SARS-CoV-2 (Fig. 1D and E). The fluorescence 
increased over time and reached a plateau within 16 to $24 \mathrm{hpi}$ (Fig. 1E), showing that the signal

detected in the flow cytometry-based assays corresponded to viral replication and not to input particles. These kinetics were in agreement with real-time quantitative reverse transcription PCR (qRT-PCR) monitoring over time the amount of SARS-CoV-2 genome (Fig. $1 F$ ).

To evaluate the production and release of de novo infectious viral particles, we infected Caco-2 and Vero cells and quantified virus production up to 24 hpi by $50 \%$ tissue culture infective dose assay (TCID50). Infectious progeny viruses were found to be released from infected cells as early as 8-12 hpi (Fig. 1G). Virus replication kinetics and de novo virus release was found to be 143 similar in Calu-3 and A549* cells (data not shown). Altogether, our analysis revealed that SARS-

144 CoV-2 completes one round of infection, from virus binding and entry to replication and release of 145 de novo infectious particles, within $8 \mathrm{~h}$ in Caco-2 cells and somewhat longer in Vero cells, i.e., 146 between 8 and $12 \mathrm{~h}$. In all the further experiments, as we aimed at characterizing SARS-CoV-2 entry mechanisms therefore we used MOls allowing the infection of about $20 \%$ of the cells and limited our assays to $8 \mathrm{hpi}$.

\section{SARS-CoV-2 Makes a Differential Use of Host Cell Proteases for Infectious Penetration}

150 To evaluate the role of the cell surface TMPRSS2 and endolysosomal cathepsin $L$ proteases in 151 the entry mechanisms of SARS-CoV-2, we used aprotinin and SB412515, respectively, to selectively inhibit the two proteases. As expected, no noticeable effect was observed when aprotinin was added to TMPRSS2-negative (TMPRSS2-) cells (A549* and Vero cells) prior to infection (Fig. 2A). In agreement with previous work (25), we observed that aprotinin reduced SARS-CoV-2 infection in a dose-dependent manner in the cells that express TMPRSS2 (Calu-3 and Caco-2 cells) (Fig. 2A). Conversely, SB412515 effectively prevented the infection of cells lacking TMPRSS2 (Vero and A549* cells) in a dose-dependent manner but had no effect on SARS-CoV-2 infection of Calu-3 and Caco-2 cells (Fig. 2B). The fact that aprotinin interfered with 
SARS-CoV-2 infection in Calu-3 and Caco-2 cells indicated that, even if TMPRSS2 was blocked, cathepsin L would not take over and subsequently process SARS-CoV-2. added at different times after warming to prevent further activation and penetration of the virus. In other words, we determined the time when inhibition of SARS-CoV-2 activation is no longer possible, which resulted in an increase of infection. In both TMPRSS2- cell lines (A549* and Vero cells), the SB412515 add-in time course revealed that the activation by cathepsin $L$ and the subsequent infectious penetration of SARS-CoV-2 started after a $15 \mathrm{~min}$ lag and reached a half maximal level $\left(t_{1 / 2}\right)$ within 40-60 min (Fig. 2C). Evidently, exposure of individual viruses to cathepsin L occurred non-synchronously during a time span 15-90 min after warming. The add-in time course using aprotinin showed that productive penetration was much faster in TMPRSS2+ cells (Calu- 3 and Caco-2 cells) (Fig. 2D). The $t_{1 / 2}$ of activation by TMPRSS2 was reached within

$1735-10 \mathrm{~min}$ in both cell lines. Taken together, our observations demonstrated that TMPRSS2 allowed

174 for a faster activation and penetration of SARS-CoV-2 in comparison to cells for which infection 175 depends on cathepsin L.

177 Recent reports indicated that SARS-CoV-2 infection is sensitive to lysosomotropic weak bases 178 that neutralize vacuolar $\mathrm{pH}$ such as ammonium chloride $\left(\mathrm{NH}_{4} \mathrm{Cl}\right)$ and chloroquine $(7,10,11)$. 179 However, TMPRSS2 is active at the cell surface under neutral $\mathrm{pH}$ conditions (20), unlike cathepsin $180 \mathrm{~L}$, which requires the low-pH environment typical of endolysosomes (21). To assess the 181 importance of endosomal acidification for infectious entry in cells expressing (Caco-2 and Calu-3) 182 and lacking (A549* and Vero) TMPRSS2, cells were exposed to SARS-CoV-2 in the presence of 183 increasing amounts of $\mathrm{NH}_{4} \mathrm{Cl}$ or chloroquine. Our results showed that both weak bases induced a 
dose-dependent inhibition of infection regardless of the cell type and of TMPRSS2 expression (Fig. $3 A$ and $3 B$ ). However, the dose to inhibit $50 \%$ of SARS-CoV-2 infection $\left(\right.$ IC $\left._{50}\right)$ was found to be significantly lower in cells devoid of TMPRSS2 compared to cells expressing the protease, reaching a 200 -fold difference for chloroquine (Table 1).

To validate the observation that TMPRSS2+ cells were less dependent on endosomal acidification for SARS-CoV-2 infection, we made used of Bafilomycin A1 and Concanamycin B, which are inhibitors of the vacuolar-type proton-ATPases (vATPases). Incubation of cells with increasing amounts of the two drugs resulted in a dose-dependent inhibition of SARS-CoV-2 infection (Fig. 3C and $3 D$ ). Importantly, the inhibition was marginal with $10 \mathrm{nM}$ of Bafilomycin $\mathrm{A} 1$ and Concanamycin B in TMPRSS2+ cells (Caco-2 and Calu-3), and the decrease in infection did not exceed $50-80 \%$ at $50 \mathrm{nM}$ of Concanamycin B. For comparison, infection with Uukuniemi virus (UUKV), a late-penetrating virus that relies on low $\mathrm{pH}$ in late endosomes (LE) for penetration (26), is strongly inhibited in the presence of 2 to $10 \mathrm{nM}$ of Concanamycin B or Bafilomycin $\mathrm{A} 1$ (26). From these results, it was evident that, similar to the lysosomotropic weak bases, SARS-CoV-2 infection appeared to be significantly less sensitive to vATPase inhibitors in TMPRSS2+ cells (Caco-2 and Calu-3) in comparison to cells lacking the protease (Vero and A549* cells) (Table 1).

\section{SARS-CoV-2 Can Use Two Distinct Routes to Enter and Infect Target Cells}

Our results suggested that SARS-CoV-2 infection relied more on endosomal acidification in cells devoid of TMPRSS2 than cells expressing the protease. To pursue this possibility, we determined the kinetics of the acidification step required for the infectious penetration of SARS-CoV-2 into TMPRSS2- cells. We took advantage of the fact that the neutralization of endosomal $\mathrm{pH}$ is nearly instantaneous upon $\mathrm{NH}_{4} \mathrm{Cl}$ addition to the extracellular medium (27). Virus particles were first allowed to attach to $A 549^{*}$ and Vero cells on ice. Entry was then synchronized by switching cells rapidly to $37^{\circ} \mathrm{C}$, and $\mathrm{NH}_{4} \mathrm{Cl}$ was added at different times. In $\mathrm{A} 549^{*}$ and Vero cells, viruses passed the $\mathrm{NH}_{4} \mathrm{Cl}$-sensitive step 15 min after cell warming, and the $t_{1 / 2}$ was reached within 50 min (Fig. 
$3 E$ ). Overall, the kinetics of SARS-CoV-2 acid-activated penetration closely resembled the time course of cathepsin L-dependent activation in the absence of TMPRSS2 (Fig. 2C).

In Calu-3 and Caco-2 cells, both of which express TMPRSS2, it was not possible to determine the timing of the acid-requiring step. We failed to detect SARS-CoV-2-infected cells even by adding $\mathrm{NH}_{4} \mathrm{Cl}$ several hours after transferring the cells from 4 to $37^{\circ} \mathrm{C}$ (Fig. $3 E$ ). In samples

214 where $\mathrm{NH}_{4} \mathrm{Cl}$ was omitted, infection was readily detectable with $17 \%$ of Calu-3 and Caco-2 cells 215 infected (data not shown) suggesting that the weak base interferes with SARS-CoV-2 replication 216 in these two cell lines. It is highly likely that $\mathrm{NH}_{4} \mathrm{Cl}$ disrupts TMPRSS2+ cell-specific functions that 217 are important for SARS-CoV-2 replication. $\mathrm{NH}_{4} \mathrm{Cl}$ not only neutralizes the intracellular $\mathrm{pH}$ but also 218 alters all endosomal, lysosomal, and trans-Golgi-network functions that are acid dependent (28).

As an alternative method to alter endosomal $\mathrm{pH}$, we used Concanamycin $\mathrm{B}$ instead of $\mathrm{NH}_{4} \mathrm{Cl}$ and added the vATPase inhibitor to Caco-2-cell-bound virus at different times after warming. The

221 time course showed that SARS-CoV-2 infection was insensitive to the Concanamycin B add-in as 222 early as a few seconds after shifting Caco-2 cells to $37^{\circ} \mathrm{C}$ (Fig. $\left.3 F\right)$. In a marked contrast, infectious 223 entry of UUKV started after 15 min and had not reached a maximum $2 \mathrm{~h}$ after cell warming. As 224 expected, SARS-CoV-2 passed the Concanamycin B-sensitive step in Vero cells within less than $22515 \mathrm{~min}$, and infectious entry reached a plateau value after $45 \mathrm{~min}$, somewhat faster than in using $226 \mathrm{NH}_{4} \mathrm{Cl}$ (Fig. 3E). This difference in Vero sensitivity to endosomal pH may be that Concanamycin 227 B not only interferes with endosomal functions that are acid dependent but also indirectly with the 228 maturation of endosomes. However, unlike $\mathrm{NH}_{4} \mathrm{Cl}$, it was apparent that Concanamycin $\mathrm{B}$ had no 229 adverse effect on SARS-CoV-2 replication in all these experiments. Taken together, these results 230 strongly suggested that SARS-CoV-2 can use two different routes to enter and infect target cells, 231 i.e., fast pH-independent penetration in TMPRSS2+ cells (Fig. 2D and $3 F$ ) and slow acid-activated 232 entry in cells lacking TMPRSS2 (Fig. 2C and $3 E$ ). 


\section{SARS-CoV-2 Relies on Endolysosomal Maturation for Infection of TMPRSS2- Cells}

234

235

236

237

238

The timing of acid-dependent and protease-activated steps suggested that SARS-CoV-2 penetration might occur from endolysosomes in cells devoid of TMPRSS2 and from the plasma membrane or early endosomes (EEs) in TMPRSS2+ cells. To determine whether SARS-CoV-2 requires reaching the endolysosomal compartments for the productive infection of TMPRSS2cells, we exploited the small GTPase Rab7a, which is a key player of LE maturation and function. TMPRSS2- Vero cells were transfected with DNA plasmids encoding the wild-type (wt), the dominant-negative (Rab7a T22N), and the constitutively active (Rab7a Q67L) forms of Rab7a tagged with the enhanced green fluorescent protein (EGFP) prior to infection with SARS-CoV-2. Transfected cells were selected for different levels of EGFP expression and then analyzed for infection. Increasing expression of the wt molecule of Rab7a facilitated SARS-CoV-2 infection. On the contrary, increasing expression of both mutants of Rab7a, which abrogates the maturation of newly formed LEs $(26,29)$, resulted in a $50 \%$ decrease in infection (Fig. $4 A$ ), indicating that the virus cannot fuse in Rab7a T22N- and Q67L-late endosomal vesicles. This result suggested that proper maturation of LEs is mandatory for the cathepsin L-dependent infectious entry of SARSCoV-2.

LE maturation relies on microtubule-mediated transport to the nuclear periphery and proteasome activity $(26,29)$. Treatment of Vero cells with colcemid, a drug that interferes with microtubule polymerization, resulted in a 30\%-45\% decrease in infection (Fig. 4B). Additionally, late endosomal penetration of IAV and UUKV has been shown to be sensitive to free ubiquitin depletion produced by the proteasome inhibitor MG-132 $(26,30)$. Therefore, to determine if free ubiquitin was required for SARS-CoV-2 infection, A549* and Vero cells were treated with MG-132. Results show that SARS-CoV-2 infection was strongly inhibited in the presence of MG-132 in both cell lines (Fig. 4C). The calculated $\mathrm{IC}_{50}$ confirmed the high proficiency (4 to $17 \mathrm{nM}$ ) of MG-132 to interfere with the cathepsin L-mediated SARS-CoV-2 entry route (Table 1). 
To determine the kinetic of the MG-132-sensitive step in the entry process, we followed the same experimental procedure used to determine the kinetics of endosomal acidificationdependent and cathepsin L-mediated activation of SARS-CoV-2 (Fig. 2C and 3E) but utilizing MG132 instead of protease inhibitor and $\mathrm{NH}_{4} \mathrm{Cl}$. Briefly, viruses were bound to $\mathrm{A} 549^{*}$ and Vero cells at a low $\mathrm{MOI}$ on ice, and then promptly switched to $37^{\circ} \mathrm{C}$ before adding $\mathrm{MG}-132$ at different times. After a 15 min lag, infectious penetration occurred asynchronously between 30 and 60 min, with a $t_{1 / 2}$ within 40-50 min (Fig. 4D). This time course was consistent with endolysosomal maturation, which usually lasts 30-60 min (31). Altogether, these results show that the cathepsin L-dependent SARS-CoV-2 infection depends on endolysosome maturation in TMPRSS2- A549* and Vero cells. Interestingly, LE maturation was also required in TMPRSS2+ cells (Calu-3 and Caco-2 cells) as SARS-CoV-2 infection was reduced by colcemid in a dose-dependent manner in both cell lines (Fig. 4E). Though the inhibition was efficient, the $\mathrm{IC}_{50}$ values of $\mathrm{MG}-132$ were one to three logs higher in TMPRSS2+ cells compared to TMPRSS2- cells (Fig. 4F). As shown in Fig. 4G, infection of Calu-3 and Caco-2 cells was not readily detectable when MG-132 was added 2 hpi. Together,

272 the data suggest that MG-132 impaired viral replication in these assays and not the TMPRSS2273 dependent SARS-CoV-2 entry process.

\section{Low pH Is Not Essential for SARS-CoV-2 Membrane Fusion}

275 The penetration of enveloped viruses into the cytosol involves fusion between the viral envelope

276 and a cell membrane. In most cases, endosomal acidification contributes to activate viral 277 glycoproteins and is used as a cue to trigger fusion (12). SARS-CoV-2 does not rely on endosomal 278 acidification to enter TMPRSS2+ cells, which suggests that the virus does not rely on low $\mathrm{pH}$ for 279 membrane fusion but solely for the activation of cathepsin $L$ in cells lacking TMPRSS2. mechanisms, we first assessed the possibility to inactivate the virus with acidic buffers prior 282 infection. In such an assay, the virus undergoes a transition toward the post-fusion state at the 
283

284

285

286

287

288

289

290

291

292

293

294

295

296

297

298

299

300

301

302

optimal $\mathrm{pH}$. If the transition is irreversible, the spike protein is no longer able to fuse with targetcell membranes, and thus, the viral particles are rendered non-infectious. With this approach, we found that about $50 \%$ of viruses were still infectious in Caco-2 and Vero cells, even after an exposition to buffers at $\mathrm{pH} \sim 5$ for $10 \mathrm{~min}$ (Fig. 5A). Semliki forest virus (SFV) is an early-penetrating virus that has a Class-II viral fusion glycoprotein with an irreversible priming step triggered at a $\mathrm{pH}$-activation threshold of 6.2 (26). In contrast to SARS-CoV-2, infection by low pH-pretreated SFV was reduced by $70-80 \%$ at $\mathrm{pH} \sim 6.0$ and below (Fig. $5 B$ ).

To further investigate the influence of low $\mathrm{pH}$ on SARS-CoV-2 fusion, we then evaluated the capacity of SARS-CoV-2 to mediate cell-cell fusion ("fusion-from-within") as described for unrelated viruses (32). To this end, we used Vero cells as they are negative for TMPRSS2, which makes it a convenient model to monitor proteolytic activation of the S protein at the cell surface by exogenous proteases. Briefly, confluent monolayers of Vero cells were infected with SARSCoV-2 for $24 \mathrm{~h}$, and the infected cells were then subjected to buffers of different $\mathrm{pH}$ values. The extent of cell-cell fusion, i.e., formation of syncytia, was determined using a fusion index that expresses the average number of fusion events per original mononucleated cell (33). The index reaches 1 when all the nuclei in the microscope field are present in a single cell, and the value is 0 when all cells have one nucleus each. Formation of syncytia with two or more nuclei was observed regardless of the $\mathrm{pH}$ of the buffer (Fig. $5 C$ ), and the fusion index did not significantly differ when cells were treated with low pH or neutral buffers (Fig. 5D). Together, our observations strongly suggested that low $\mathrm{pH}$ is not required for the SARS-CoV-2 fusion mechanisms.

\section{Proteolytic Processing Is Sufficient and Necessary for SARS-CoV-2 Fusion}

The results suggested that acidification is not required to prompt viral fusion and that proteolytic processing might be sufficient. As furin and TMPRSS2 are believed to mediate the activation of the SARS-CoV-2 spike proteins, we then evaluated the ability of the two proteases to trigger SARS-CoV-2 activation and fusion using our flow cytometry-based infection analysis and syncytia- 
forming assay. In the following series of experiments, exogenous trypsin was used to mimic

TMPRSS2 at the cell surface as the two enzymes are closely related and both belong to the group

of trypsin-like proteases. The use of exogenous cathepsin $L$ was excluded because the enzyme

is only active at $\mathrm{pH} \sim 5$, which would have made it impossible to distinguish between an effect due

312 to low $\mathrm{pH}$ or proteolytic cleavage.

Viral particles were first subjected to proteases prior to being added to Caco-2 and Vero

cells. We found that infection increased as much as 2- to 3-fold following the SARS-CoV-2

proteolytic processing by trypsin, whereas the pre-exposure of particles to furin had no apparent

effect (Fig. 6A). Similar results were obtained with our cell-cell fusion assay. Large syncytia with

317 five or more nuclei were observed when infected Vero cells were exposed to trypsin (Fig. 6B).

318 Contrary to trypsin-treated cells, no difference was observed after furin treatment in comparison

319 to the mock-treated samples, for which the only cells with more than one nucleus were those

320 dividing (Fig. 6B). Additionally, the fusion index in Vero cells was increased under trypsin treatment

321 compared to mock- and furin-treated cells (Fig. 6C). Altogether our data indicated that proteolytic

322 cleavage is sufficient and necessary for SARS-CoV-2 membrane fusion.

\section{Endosomal Acidification Is Required for Endolysosomal Proteases Priming Viral Fusion}

324 Our results support a model where endosomal acidification is not essential for SARS-CoV-2

325 membrane fusion, but SARS-CoV-2 infection relies on low $\mathrm{pH}$ for cathepsin L-dependent infection

326 in cells lacking TMPRSS2. Therefore, we tested the possibility that acid $\mathrm{pH}$ is required for the

327 activation of endolysosomal proteases that in turn trigger SARS-CoV-2 fusion. In such a scenario,

328 the spike S proteins that are already primed by proteases should no longer rely on low $\mathrm{pH}$ for

329 fusion. Indeed, we found that the fusion index was not increased when trypsin treatment was

330 followed by exposure to a decreasing pH of 7.4 to 5 (Fig. $7 A$ and $7 B$ ), the latter value being typical

331 of the luminal $\mathrm{pH}$ of endolysosomes (29). 
To further evaluate whether SARS-CoV-2 membrane fusion is low $\mathrm{pH}$-independent, viral particles were then exposed to buffers at $\mathrm{pH} \sim 5$ and subsequently subjected to proteolytic cleavage by trypsin. Our results revealed that SARS-CoV-2 infectivity was preserved when viral particles were exposed to the low-pH buffer prior to trypsin treatment in comparison to virus particles that were solely exposed to acidic pH (Fig. 7C). The infectivity also remained preserved when the virus was first subjected to trypsin and then acidification. Taken together, the results showed that endosomal acidification does not play a role in SARS-CoV-2 membrane fusion, whether it occurs before or after the proteolytic processing of viral particles. In addition, our results strongly suggested that the potential $\mathrm{pH}$-induced conformational changes in the SARS-CoV-2 spikes were neither irreversible nor detrimental for the viral fusion.

To directly test whether endosomal acidification is needed for the host cell proteases that prime SARS-CoV-2 fusion, and not for the fusion mechanisms themselves, we assessed whether preactivated viral particles no longer depend on endosomal acidification for infectious entry. For this purpose, the proteolytic processing of the virus particles was achieved with trypsin prior to the infection of A549* and Vero cells. To interfere with the acid-dependent endolysosomal proteases, the infection was carried out in the continuous presence of $50 \mathrm{nM}$ of Bafilomycin A1. As A549* and Vero cells do not express TMPRSS2, this assay allowed us to directly test the impact of extracellular protease-activated viral particles. As reported above (Fig. 3C), infection with untreated viral particles was severely hampered when proton pumps were blocked in the absence of TMPRSS2 (Fig. 7D). In stark contrast, the protease-preactivated viral particles remained infectious in the presence of Bafilomycin A1 (Fig. 7D).

The capacity of SARS-CoV-2 to infect A549* and Vero cells upon proteolytic activation,

354 despite the absence of functional endolysosomal proteases, was confirmed using $\mathrm{NH}_{4} \mathrm{Cl}$. As 355 expected, in our synchronized infection assay, untreated particles became $\mathrm{NH}_{4} \mathrm{Cl}$ insensitive 50 356 min post entry (Fig. $7 E, 7 F$, and $3 E$ ). However, when the viral particles were pretreated with 357 trypsin, no sensitivity to $\mathrm{NH}_{4} \mathrm{Cl}$ was observed (Fig. $7 E$ and $7 F$ ). These results strongly supported 
358 the view that, once activated by proteolytic cleavage, the virus is no longer dependent on

359 endosomal acidification for infection. Altogether, our data show that SARS-CoV-2 resembles other

360 CoVs in that its entry depends on diverse host cell proteases. It can use two distinct routes, where

361 either TMPRSS2 mediates its $\mathrm{pH}$-independent penetration from or close to the cell surface or

362 alternatively, it is transported to endolysosomes, where low $\mathrm{pH}$ activates cathepsin $\mathrm{L}$ that in turn

363 primes viral fusion and penetration. 


\section{Discussion}

365 The infectious entry process of CoVs is complex (3). Several host cell proteases can prime the

366 CoV spike S proteins for viral membrane fusion, but it is not yet known whether these mechanisms

367 require selective proteases or a coordinated, spatio-temporal combination of several proteases.

368 The importance of endosomal acidification in the productive penetration of all CoVs is also a 369 matter of debate. Furin, TMPRSS2, and cathepsin $L$ have all three been implicated in coronavirus

370 activation for entry $(5,7,17,22,23)$, and agents elevating endosomal pH such as chloroquine

371 have been described to interfere with infection $(7,10,11)$. SARS-CoV-2 and other CoVs have

372 apparently found a way to use diverse entry mechanisms to infect target cells and spread

373 throughout the host.

374 In this study, we developed reliable and accurate assays to investigate SARS-CoV-2

375 infection in lung, intestine, and kidney epithelial cells, from proteolytic activation to membrane

376 fusion. In agreement with other reports $(7,25)$, our results showed that SARS-CoV-2 infection was

377 sensitive to inhibitors of TMPRSS2 and cathepsin L. We further found that blocking TMPRSS2

378 abrogated infection even when the cells were expressing cathepsin L, indicating that the virus

379 does not reach endolysosomal cathepsins when TMPRSS2 is present. Others have shown that

380 infection by MERS pseudo-viruses was suppressed by trypsin-like protease inhibitors in the

381 presence of the tetraspanin CD9, while entry was unaffected but rather blocked by cathepsin

382 inhibitors in the absence of CD9 (34). These authors proposed that tetraspanins condense CoV 383 entry factors into localized positions on or close to the cell surface, allowing rapid and efficient 384 activation of viral fusion (35).

We observed that SARS-CoV-2 used two distinct routes to enter cells, one fast ( $10 \mathrm{~min})$ 386 which corresponded to the timing of TMPRSS2 activation, and the second slower (40-50 min) 387 corresponding to cathepsin L priming. Although other cellular factors are likely necessary, our 388 results support the view that TMPRSS2 is a major determinant of the SARS-CoV-2 fast entry track. 
Similar observations have been made for the human CoV 229E (hCoV-229E), which prefers cellsurface TMPRSS2 to endosomal cathepsins for cell entry (36-38). endosomal acidification for infectious penetration. Concanamycin B, which specifically inhibits vATPases and elevates endosomal $\mathrm{pH}$, affected UUKV, an enveloped virus that penetrates host cells by acid-activated membrane fusion (26), but not SARS-CoV-2. This was consistent with reports that TMPRSS2 processes CoV S and other substrates at or nearby the plasma membrane $(39,40)$, i.e., at neutral $\mathrm{pH}$. Using aprotinin, we found that half of the bound viral particles required

5-10 min to pass the TMPRSS2-dependent step. We cannot completely exclude that aprotinin was not instantaneously effective when it was added to the infected cells. In this case, the timing of TMPRSS2-requiring step was therefore faster. SARS-CoV-2 activation and penetration would then likely take place at the plasma membrane following proteolytic activation, as proposed for hCoV-229E and MERS-CoV $(37,41)$.

An alternative scenario would be that SARS-CoV-2 is sorted into the endocytic machinery regardless of the TMPRSS2 expression. The time course of TMPRSS2-requiring step resembled that of cargo sorted into EEs, circa 5-10 min (31). Another observation supporting this hypothesis was that colcemid hampered infection. This drug perturbates LE maturation by disrupting the microtubule network, and in turn, causes the accumulation and dysfunction of EEs (26). Such a strategy has been proposed for reoviruses, which use similar uptake but different trafficking depending on whether viral particles are activated or not (42). Like other CoVs (39), more functional investigations are required to determine, where exactly, from the plasma membrane or EEs, SARS-CoV-2 enters the cytosol of TMRPSS2+ cells, and whether the processing of the S 411 protein is followed by transport of the virus to downstream organelles for penetration. 
colcemid or the expression of Rab7a T22N affected SARS-CoV-2 infection. The sensitivity to MG132 mirrored observations with UUKV, IAV, and murine CoVs, which accumulated in cytosolic vesicles and failed to infect $(26,30,43)$. Others have reported that SARS-CoV-2 depends on PIKfyve for the infection of 293T cells, a line devoid of TMPRSS2 (10). PIKfyve is a 419 phosphoinositide kinase involved in the first stages of LE maturation. Collectively, our results 420 indicate that SARS-CoV-2, like other $\operatorname{CoVs}(41,44,45)$, has a dependence on functional 421 endolysosomes and cathepsins for infectious penetration when the viral particles are not activated 422 at or near the cell surface.

423 Our results suggested that the proteolytic activation of the spike S protein was sufficient and necessary for SARS-CoV-2 fusion. The Vero cells used in our virus-mediated cell-cell fusion assay did not express TMPRSS2 on the cell surface. In this assay, exogenous furin failed to promote the syncytia formation, indicating that either furin was inefficient or not sufficient to achieve the full activation of the SARS-CoV-2 protein S at the plasma membrane. The S1/S2 site exhibits a RAR motif instead the typical $\mathrm{RX}(\mathrm{R} / \mathrm{K}) \mathrm{R}$ furin one, and a recent structural study support the view that the cleavage by furin at this site in the $S$ trimers is rather low, about $30 \%(17,46,47)$. However, we found that, unlike furin, trypsin prompted the formation of syncytia, which rather supports the involvement of proteases in the target cells, such as TMPRSS2 and cathepsin L, to complete the proteolytic processing of the S protein. Others have shown that SARS-CoV-2, and also MERScells express TMPRSS2 $(16,48)$.

It is also apparent from our results that the SARS-CoV-2 progeny was not fully processed and activated. Trypsin pretreatment increased the virus infectivity. More work is evidently required

437 to decipher the SARS-CoV-2 fusion mechanism. The list of the involved host cell proteases is 438 most likely not restricted to TMPRSS2 and cathepsin L, as suggested by a recent biochemistry 439 study (49). The S proteolytic activation might involve the cleavage of other sites than S1/S2 and 440 S2', similarly to what was found for the MERS-CoV protein S (40). It is, however, tempting to 
441 postulate that the cleavage between S1 and S2 is not complete on SARS-CoV-2 particles, with

442 only one or two of the three S1/S2 sites cut by furin within S trimers. In this model, cutting all the

443 S1/S2 sites would be achieved by proteases in target cells such as TMPRSS2 and cathepsin L.

444 The fusogenic conformational change would then occur and be completed by the cleavage of the

445 S2' sites, therefore, unmasking the fusogenic units. The S1/S2 site significantly differs in amino-

446 acid residues through CoVs (17) and highly likely influences the overall viral fusion process.

447 We found that the level of virus mRNA and infectious viral progeny released in the outer

448 media was lower in the absence of TMPRSS2. The TMPRSS2-dependent entry mechanisms

449 occurred faster than the cathepsin L-activated pathway, and it might be that the early route results

450 in a more productive infection than the late-penetrating process. Separate studies support, at least

451 for some CoV strains including HCoV-229E, the view that early entry results in productive

452 infection, while late penetration would be an alternative, backup route $(35,37,38)$. Other works

453 on therapeutics have linked host cell proteases to CoV spread. Inhibitors of TMPRSS2, but not of

454 cathepsins, effectively prevent the pathogenesis of SARS-CoV in mice, suggesting that SARS-

455 CoV mainly uses cell surface proteases rather than endosomal cathepsins in vivo (50). The

456 identification of all host cell proteases involved in SARS-CoV-2 and other CoV infection, as well

457 as the tissues and organs that express them, remains an important objective to better understand

458 viral propagation and induced diseases.

459 Intriguingly, SARS-CoV-2 showed a strong resistance to acidic buffers. Exposure to $\mathrm{pH} \sim 5.0$

460 only marginally inactivated the virus, and infectivity was even rescued and enhanced by proteolytic

461 treatment. In addition, trypsin activation appeared to protect the virus from acid inactivation, which

462 could explain how it is found to infect the gastrointestinal tract in vivo. SARS-CoV-2 has evidently

463 developed a remarkable ability to adapt to an acidic environment. Interestingly, low pH has been

464 shown to switch the positioning of the receptor-binding domain in the SARS-CoV-2 S trimers,

465 which could help the virus to escape the immune system (51). Overall, this property certainly 
confers the virus the ability to sustain a high infectivity, not only within endosomes to enter host

467 cells, but also in the extracellular space, especially during the virus spread throughout the host.

468 Reports on the cell entry of SARS-CoV-2 and other CoVs often describe only one cell model

469 system, and the literature in this field remains confusing in general. Our study recapitulates within

470 a single investigation the SARS-CoV-2 entry process and provides an overview of the cellular

471 mechanisms used by SARS-CoV-2 to penetrate and infect target cells. Although it remains to be

472 confirmed under physiological conditions, we propose that SARS-CoV-2 can enter cells through

473 two distinct, mutually exclusive pathways. When target cells express TMPRSS2, the virus is

474 activated at or close to the cell surface and penetrates early in a $\mathrm{pH}$-independent manner. When

475 target cells are devoid of TMPRSS2, SARS-CoV-2 is endocytosed and sorted into the

476 endolysosomes from where the virus is activated in a $\mathrm{pH}$-dependent manner and penetrates the

477 cytosol late. With the ability to subvert diverse cell entry routes, SARS-CoV-2 has likely found a

478 way to expand the number of target tissues and organs, which certainly contributes to the broad

479 tropism of the virus in vivo. 


\section{Materials and Methods}

\section{Cells}

482 The African green monkey Vero kidney epithelial cells (ATCC CRL 1586), the human Caco-2 483 colorectal adenocarcinoma (ATCC HTB-37), the human Calu-3 lung adenocarcinoma (ATCC 484 HTB-55), and the human epithelial lung cells A549 stably expressing ACE2 (A549*; a kind gift 485 from Prof. Ralf Bartenschlager) were all maintained in Dulbecco's modified Eagle's medium 486 (DMEM) supplemented with 10\% fetal bovine serum (FBS) and 100 units. $\mathrm{mL}^{-1}$ penicillin, and 100 $487 \mu \mathrm{g} \cdot \mathrm{mL}^{-1}$ streptomycin. Baby hamster kidney cells (BHK-21) were grown in Glasgow's minimal essential medium containing 10\% tryptose phosphate broth, 5\% FBS, 100 units. $\mathrm{mL}^{-1}$ penicillin, and $100 \mu \mathrm{g} \cdot \mathrm{mL}^{-1}$ streptomycin. All cell lines were grown in an atmosphere of $5 \% \mathrm{CO}_{2}$ in air at

491 Aldrich.

\section{Viruses}

493 SARS-CoV-2 (strain BavPat1) was obtained from Prof. Christian Drosten at the Charité in Berlin, 494 Germany, and provided via the European Virology Archive. The virus was amplified in Vero cells 495 and working stocks were used after three passages. Uukuniemi (UUKV) and Semliki forest (SFV) 496 viruses were previously described and amplified in BHK-21 cells $(52,53)$. The MOI is given 497 according to the titer determined by plaque- or foci-forming unit assay for each cell line. When 498 indicated, the titer was obtained by TCID50.

\section{Antibodies, reagents, and plasmids}

500 The mouse mAb against the SARS-CoV nucleoprotein NP (40143-MM05) was purchased from 501 Sino biologicals and used at dilutions of 1:500 for flow cytometry analysis and 1:1,000 for titration 502 in TCID50 assays. The rabbit polyclonal antibody U2 targets all the UUKV structural proteins and 503 was used at a dilution of 1:4,000 for immunohistochemistry (54). The mouse mAb 8B11A3 against 504 the UUKV nucleoprotein N was a kind gift from Ludwig Institute for Cancer Research (Stockholm, 
Sweden) (55). The mouse mAb against the SFV glycoprotein E2 was kindly provided by Prof.

E2 were used at a dilution of 1:400 for flow cytometry analysis. The rabbit antibodies against TMPRSS2 (ab92323) and actin (A2066) were obtained from Abcam and Sigma, respectively. The mouse mAb against cathepsin L (BMS1032) and $\alpha$-tubulin (T5158) were bought from Thermo

510 Fisher Scientific and Sigma, respectively. Anti-mouse secondary antibodies were conjugated to 511 Alexa Fluor (AF) 405 (Molecular Probes), AF488 (Molecular Probes), IRDye 700 (LI-COR), IRDye $512800 \mathrm{CW}$ (LI-COR), and horseradish peroxidase (HRP; Vector Laboratories). Anti-rabbit secondary 513 antibodies conjugated to IRDye $800 \mathrm{CW}$ were purchased from $\mathrm{LI}-\mathrm{COR}$. $\mathrm{NH}_{4} \mathrm{Cl}$ (Sigma), aprotinin 514 (Cayman Chemical), and chloroquine diphosphate (Sigma) stocks were dissolved in water. Bafilomycin A1 (BioViotica), Concanamycin B (BioViotica), SB412515 (Cayman Chemical), colcemid (Cayman Chemical), and MG-132 (Selleck Chemicals) were all dissolved in DMSO.

517 Furin and Trypsin were purchased from R\&D and Sigma, respectively. Plasmids encoding EGFPtagged Rab7a, Rab7a T22N, and Rab7a Q67L have been described elsewhere (26).

\section{Protein analysis}

520 Cells were lysed with phosphate buffer saline (PBS) containing $0.1 \%$ Triton X-100 (Merck 521 Millipore), according to a standard procedure (54). Cell lysates were then diluted in LDS sample 522 buffer (Thermo Fisher Scientific) and analyzed by SDS-PAGE (Nu-PAGE Novex 10\% Bis-Tris 523 gels; Thermo Fisher Scientific). Proteins were subsequently transferred to polyvinylidene 524 difluoride membranes (iBlot transfer stacks; Thermo Fisher Scientific). The membranes were first 525 blocked with Intercept blocking buffer (LI-COR) and then incubated with primary antibodies against 526 TMPRSS2, cathepsin L, actin, and $\alpha$-tubulin, all diluted in Tris-buffered saline containing $0.1 \%$ 527 Tween and Intercept blocking buffer (1:1,000, 1:400, 1:5,000, and 1:2,000, respectively). After extensive washing, the membranes were incubated with the corresponding secondary anti- 
530 were analyzed with a LI-COR Odyssey CLx scanner, or alternatively, detected with SuperSignal

531 West Pico PLUS chemiluminescent substrate (Thermo Fisher Scientific) and an iNTAS ECL

532 Chemostar analyzer.

\section{Virus infection}

534 Cells were exposed to viruses at the indicated MOls in the presence of $2 \%$ FBS for $1 \mathrm{~h}$ at $37^{\circ} \mathrm{C}$.

535 Virus input was then replaced by complete culture medium, and infected cells were incubated for

$5368 \mathrm{~h}$ before fixation. For virus-mediated cell-cell fusion, Vero cells were infected for $24 \mathrm{~h}$. Cells that

537 transiently express EGFP-Rab7a and related mutants were infected $18 \mathrm{~h}$ post-transfection. For

$538 \mathrm{pH}$-inactivation, citric acid, 2-(N-morpholino)-ethanesulfonic acid (MES), and 4-(2-hydroxyethyl)-

539 1-piperazineethanesulfonic acid (HEPES) were used as buffers at $100 \mathrm{mM}$ as follow, $\mathrm{pH}<5.5$,

$5405.5<\mathrm{pH}<6.5$, and $6.5<\mathrm{pH}$, respectively. Virus inputs were exposed to buffers at the indicated

$541 \mathrm{pH}$ for $10 \mathrm{~min}$ at $37^{\circ} \mathrm{C}$ and then to buffers at neutral $\mathrm{pH}$ prior infection. For furin- or trypsin-

542 activation, SARS-CoV-2 was pretreated with furin $\left(1 \mu \mathrm{g} \cdot \mathrm{mL}^{-1}\right)$ or trypsin $\left(100 \mu \mathrm{g} \cdot \mathrm{mL}^{-1}\right)$,

543 respectively, for $15 \mathrm{~min}$ at $37^{\circ} \mathrm{C}$ and allowed to infect cells. For inhibition assays, cells were

544 pretreated with drugs for $30 \mathrm{~min}$ at $37^{\circ} \mathrm{C}$, apart from colcemid pretreatment that lasted $3 \mathrm{~h}$ on ice,

545 and then exposed to viruses in the continuous presence of the inhibitors. For inhibitor add-in time

546 courses, virus binding to cells was synchronized on ice for $90 \mathrm{~min}$. Cells were then rapidly warmed

547 to $37^{\circ} \mathrm{C}$, and SB412515 $(10 \mu \mathrm{M})$, aprotinin $(30 \mu \mathrm{M}), \mathrm{NH}_{4} \mathrm{Cl}$ (at indicated concentrations),

548 Concanamycin B (50 nM), and MG-132 (at indicated concentrations) were added at indicated

549 times. Cells were subsequently incubated at $37^{\circ} \mathrm{C}$ and harvested $8 \mathrm{~h}$ after the warm shift. Infection

550 was monitored by either flow cytometry, fluorescence microscopy, or qRT-PCR. When infection

551 was analyzed by microscopy, cells were seeded on Lab-Tek or iBIDI glass bottom 8-well chamber

552 slides. 


\section{DNA transfection}

554 As previously described (56), Vero cells were transfected with $750 \mathrm{ng}$ of plasmids using 555 Lipofectamine 2000 (Invitrogen) in 24-well-plates according to the manufacturer's 556 recommendations and washed $5 \mathrm{~h}$ later.

\section{Immunofluorescence microscopy}

558 Fluorescence microscopy was extensively described in (57). Briefly, infected cells were rinsed 559 with PBS, permeabilized with $0.5 \%$ Triton X-100 (Sigma) for $15 \mathrm{~min}$ at room temperature (RT), 560 and stained with primary antibodies diluted in PBS for $1 \mathrm{~h}$ at RT. Subsequently, cells were 561 extensively washed and incubated with secondary antibodies in the presence of 4',6-diamidino-2562 phenylindole (DAPI, Molecular Probes) for $45 \mathrm{~min}$ at RT. Samples were imaged with an 563 epifluorescence microscope Nikon Eclipse Ti-S (Nikon), whilst a Leica TCS SP8 confocal 564 microscope was used to image syncytia.

\section{Flow cytometry}

566 The flow cytometry-based infection assay has been described previously (53). Briefly, infected 567 cells were fixed with $4 \%$ formaldehyde for 30 min at RT and permeabilized with $0.1 \%$ saponin 568 (Serva). Cells were then exposed to primary antibody at RT for $1 \mathrm{~h}$, washed, and subsequently 569 incubated with secondary anti-mouse antibodies at RT for another $1 \mathrm{~h}$. Infected cells were 570 quantified with a FACSCelesta cytometer (Becton Dickinson) and FlowJo software (TreeStar).

\section{Virus RNA quantification}

572 As previously reported (58), RNA was harvested from cells using the NuceloSpin RNA extraction

573 kit (Machery-Nagel) according to manufacturer's instructions. The cDNA was synthesized using 574 iSCRIPT reverse transcriptase (BioRad) from $250 \mathrm{ng}$ of total RNA as per supplier 575 recommendations. q-PCR was performed using iTaq SYBR green (BioRad) following the 576 manufacturer's instructions for the SARS-CoV-2 genome using the forward primer, 
577 GCCTCTTCTCGTTCC, and the reverse primer, AGCAGCATCACCGCC. HPRT1 was used as a

578 housekeeping gene using the forward primer, CCTGGCGTCGTGATTAGTGAT, and reverse 579 primer, AGACGTTCAGTCCTGTCCATAA.

\section{Virus titration by TCID50 assay}

581 Confluent monolayers of Vero and Caco-2 cells in 96-well plates were infected with 10-fold serial

582 dilutions of SARS-CoV-2. Infected cells were fixed $24 \mathrm{hpi}$ and subjected to immunostaining using 583 the primary mouse mAb anti-SARS-CoV-2 NP and then the secondary anti-mouse antibody 584 800CW (1:10,000). Samples were finally scanned on LI-COR.

\section{Cell-cell fusion}

586 Infected cells were washed in PBS and treated with DMEM containing $0.2 \%$ bovine serum albumin 587 (Gibco) buffered at pH 7.4, 6.0, or 5.0 using $30 \mathrm{mM}$ of HEPES, MES, or citric acid, respectively, 588 for $5 \mathrm{~min}$ at $37^{\circ} \mathrm{C}$. Alternatively, infected cells were exposed to furin $\left(1 \mu \mathrm{g} \cdot \mathrm{mL}^{-1}\right)$ and trypsin $(100$ $589 \mu \mathrm{g} \cdot \mathrm{mL}^{-1}$ ) for $5 \mathrm{~min}$ at $37^{\circ} \mathrm{C}$, and when indicated, followed by acidification of the culture medium as 590 described above. Subsequently, cells were washed and incubated in complete medium for 50 min, 591 and the cytosol stained with CellMask Deep Red (1:1,000, Molecular Probes) for 10 min at $37^{\circ} \mathrm{C}$. 592 After fixation, cells were rinsed with PBS, and nuclei stained with Hoechst $33258\left(0.5 \mu \mathrm{g} \cdot \mathrm{mL}^{-1}\right.$, 593 Thermo Fisher Scientific). Syncytia were monitored by fluorescence microscopy as described 594 below. Fusion was quantified by counting the number of cells and nuclei present in a microscope 595 field. A fusion index $(f)$ was calculated according to the equation $f=(1-[c / n])$, where $c$ is the 596 number of cells in a field after fusion and $n$ the number of nuclei. An average field contained 5059760 nuclei.

\section{Statistical analysis}

599 The data shown are representative of at least three independent experiments. Values are given 600 as the means of duplicate \pm standard error of mean or triplicates \pm standard deviations. Graph 
bioRxiv preprint doi: https://doi.org/10.1101/2020.12.22.423906; this version posted December 23, 2020. The copyright holder for this preprint (which was not certified by peer review) is the author/funder, who has granted bioRxiv a license to display the preprint in perpetuity. It is made available under aCC-BY-NC-ND 4.0 International license.

601 plotting of numerical values, as well as the statistics, were achieved with GraphPad Prism v5.00

602 (GraphPad Software). Statistical methods and parameters are indicated in the figure legends

603 when applicable. P-values are shown when statistical differences are significant. 


\section{Acknowledgments}

605 This work was supported by grants from CellNetworks Research Group funds, Heidelberg, and

606 from the Deutsche Forschungsgemeinschaft (DFG) project numbers LO-2338/1-1 and LO-2338/3-

607 1) to PYL, project numbers 415089553 (Heisenberg program), 240245660 (SFB1129), 608278001972 (TRR186), and 272983813 (TRR179) to SB, and project 416072091 to MS. This work

609 was also supported by INRAE starter funds, IDEX-Impulsion 2020 (University of Lyon), and

610 FINOVI (Fondation pour l'Université de Lyon), all to PYL. We acknowledge funding from the

611 German Academic Exchange Service (DAAD, Research Grant 57440921) to PD. We thank Felix

612 Rey and Ari Helenius for fruitful discussions. 


\section{References}

614 1. Modrow S, Falke D, Truyen U, \& Schätzl H (2013) Viruses with Single-Stranded, Positive-

615 Sense RNA Genomes. Molecular Virology, eds Modrow S, Falke D, Truyen U, \& Schätzl H

616 (Springer, Berlin, Heidelberg), pp 185-349.

617 2. Paules Cl, Marston HD, \& Fauci AS (2020) Coronavirus Infections-More Than Just the 618 Common Cold. JAMA 323(8):707-708.

619 3. Hartenian E, et al. (2020) The molecular virology of coronaviruses. J Biol Chem 295(37):12910-12934.

4. Caly L, et al. (2020) Isolation and rapid sharing of the 2019 novel coronavirus (SARS-CoV-2) from the first patient diagnosed with COVID-19 in Australia. Med J Aust 212(10):459-462.

5. Matsuyama S, et al. (2020) Enhanced isolation of SARS-CoV-2 by TMPRSS2-expressing 117(13):7001-7003.

6. Turonova B, et al. (2020) In situ structural analysis of SARS-CoV-2 spike reveals flexibility mediated by three hinges. Science 370(6513):203-208.

7. Hoffmann M, et al. (2020) SARS-CoV-2 Cell Entry Depends on ACE2 and TMPRSS2 and Is Blocked by a Clinically Proven Protease Inhibitor. Cell 181(2):271-280 e278.

8. Clausen TM, et al. (2020) SARS-CoV-2 Infection Depends on Cellular Heparan Sulfate and ACE2. Cell.

9. Daly JL, et al. (2020) Neuropilin-1 is a host factor for SARS-CoV-2 infection. Science.

10. Ou X, et al. (2020) Characterization of spike glycoprotein of SARS-CoV-2 on virus entry and its immune cross-reactivity with SARS-CoV. Nat Commun 11(1):1620. novel coronavirus (2019-nCoV) in vitro. Cell Res 30(3):269-271.

12. Harrison SC (2015) Viral membrane fusion. Virology 479-480:498-507. 
638

639

640

641

642

643

644

645

646

647

648

649

650

651

652

653

654

655

656

657

658

659

660

661

662

663

13. Walls AC, et al. (2020) Structure, Function, and Antigenicity of the SARS-CoV-2 Spike Glycoprotein. Cell 181(2):281-292 e286.

14. Wrapp D, et al. (2020) Cryo-EM structure of the 2019-nCoV spike in the prefusion conformation. Science 367(6483):1260-1263.

15. Lai AL, Millet JK, Daniel S, Freed JH, \& Whittaker GR (2017) The SARS-CoV Fusion Peptide Forms an Extended Bipartite Fusion Platform that Perturbs Membrane Order in a CalciumDependent Manner. J Mol Biol 429(24):3875-3892.

16. Buchrieser J, et al. (2020) Syncytia formation by SARS-CoV-2-infected cells. EMBO J:e106267.

17. Bestle D, et al. (2020) TMPRSS2 and furin are both essential for proteolytic activation of SARS-CoV-2 in human airway cells. Life Sci Alliance 3(9).

18. Coutard B, et al. (2020) The spike glycoprotein of the new coronavirus 2019-nCoV contains a furin-like cleavage site absent in CoV of the same clade. Antiviral Res 176:104742.

19. Hoffmann M, Kleine-Weber H, \& Pohlmann S (2020) A Multibasic Cleavage Site in the Spike Protein of SARS-CoV-2 Is Essential for Infection of Human Lung Cells. Mol Cell 78(4):779784 e775.

20. Choi SY, Bertram S, Glowacka I, Park YW, \& Pohlmann S (2009) Type II transmembrane serine proteases in cancer and viral infections. Trends Mol Med 15(7):303-312.

21. Mohamed MM \& Sloane BF (2006) Cysteine cathepsins: multifunctional enzymes in cancer. Nat Rev Cancer 6(10):764-775.

22. Shang J, et al. (2020) Cell entry mechanisms of SARS-CoV-2. Proceedings of the National Academy of Sciences of the United States of America 117(21):11727-11734.

23. Liu T, Luo S, Libby P, \& Shi GP (2020) Cathepsin L-selective inhibitors: A potentially promising treatment for COVID-19 patients. Pharmacol Ther 213:107587.

24. Zecha J, et al. (2020) Data, Reagents, Assays and Merits of Proteomics for SARS-CoV-2 Research and Testing. Mol Cell Proteomics 19(9):1503-1522. 
664

665

666

667

668

25. Bojkova D, et al. (2020) Aprotinin Inhibits SARS-CoV-2 Replication. Cells 9(11).

26. Lozach PY, et al. (2010) Entry of bunyaviruses into mammalian cells. Cell host \& microbe $7(6): 488-499$.

27. Ohkuma S \& Poole B (1978) Fluorescence probe measurement of the intralysosomal pH in living cells and the perturbation of $\mathrm{pH}$ by various agents. Proceedings of the National Academy of Sciences of the United States of America 75(7):3327-3331.

28. Helenius A (2013) Virus entry: what has pH got to do with it? Nat Cell Biol 15(2):125.

29. Lozach PY, Huotari J, \& Helenius A (2011) Late-penetrating viruses. Current opinion in virology 1(1):35-43.

30. Khor R, McElroy LJ, \& Whittaker GR (2003) The ubiquitin-vacuolar protein sorting system is selectively required during entry of influenza virus into host cells. Traffic 4(12):857-868.

31. Huotari J \& Helenius A (2011) Endosome maturation. EMBO J 30(17):3481-3500.

32. Bratt MA \& Gallaher WR (1969) Preliminary analysis of the requirements for fusion from within and fusion from without by Newcastle disease virus. Proceedings of the National Academy of Sciences of the United States of America 64(2):536-543.

33. White J, Matlin K, \& Helenius A (1981) Cell fusion by Semliki Forest, influenza, and vesicular stomatitis viruses. The Journal of cell biology 89(3):674-679.

34. Earnest JT, et al. (2017) The tetraspanin CD9 facilitates MERS-coronavirus entry by scaffolding host cell receptors and proteases. PLoS pathogens 13(7):e1006546.

35. Hantak MP, Qing E, Earnest JT, \& Gallagher T (2019) Tetraspanins: Architects of Viral Entry and Exit Platforms. J Virol 93(6).

36. Bertram S, et al. (2013) TMPRSS2 activates the human coronavirus 229E for cathepsinindependent host cell entry and is expressed in viral target cells in the respiratory epithelium. $J$ Virol 87(11):6150-6160.

37. Shirato K, Kanou K, Kawase M, \& Matsuyama S (2017) Clinical Isolates of Human Coronavirus 229E Bypass the Endosome for Cell Entry. J Viro/91(1). 
690

691

692

693

694

695

696

697

698

699

700

701

702

703

704

705

706

707

708

709

710

711

712

713

714

715

38. Shirato K, Kawase M, \& Matsuyama S (2018) Wild-type human coronaviruses prefer cellsurface TMPRSS2 to endosomal cathepsins for cell entry. Virology 517:9-15.

39. Wang L \& Xiang Y (2020) Spike Glycoprotein-Mediated Entry of SARS Coronaviruses. Viruses 12(11).

40. Kleine-Weber H, Elzayat MT, Hoffmann M, \& Pohlmann S (2018) Functional analysis of potential cleavage sites in the MERS-coronavirus spike protein. Sci Rep 8(1):16597.

41. Qian Z, Dominguez SR, \& Holmes KV (2013) Role of the spike glycoprotein of human Middle East respiratory syndrome coronavirus (MERS-CoV) in virus entry and syncytia formation. PLoS One 8(10):e76469.

42. Boulant S, et al. (2013) Similar uptake but different trafficking and escape routes of reovirus virions and infectious subvirion particles imaged in polarized Madin-Darby canine kidney cells. Mol Biol Cell 24(8):1196-1207.

43. Yu GY \& Lai MM (2005) The ubiquitin-proteasome system facilitates the transfer of murine coronavirus from endosome to cytoplasm during virus entry. J Virol 79(1):644-648.

44. Simmons G, et al. (2005) Inhibitors of cathepsin L prevent severe acute respiratory syndrome coronavirus entry. Proceedings of the National Academy of Sciences of the United States of America 102(33):11876-11881.

45. Kawase M, Shirato K, Matsuyama S, \& Taguchi F (2009) Protease-mediated entry via the endosome of human coronavirus 229E. J Virol 83(2):712-721.

46. Wrobel AG, et al. (2020) SARS-CoV-2 and bat RaTG13 spike glycoprotein structures inform on virus evolution and furin-cleavage effects. Nat Struct Mol Biol 27(8):763-767.

47. Cai Y, et al. (2020) Distinct conformational states of SARS-CoV-2 spike protein. Science 369(6511):1586-1592.

48. Shirato K, Kawase M, \& Matsuyama S (2013) Middle East respiratory syndrome coronavirus infection mediated by the transmembrane serine protease TMPRSS2. J Virol 87(23):1255212561. 
716

717

718

719

720

721

722

723

724

725

726

727

728

729

730

731

732

733

734

735

736

737

49. Jaimes JA, Andre NM, Millet JK, \& Whittaker GR (2020) Structural modeling of 2019-novel coronavirus (nCoV) spike protein reveals a proteolytically-sensitive activation loop as a distinguishing feature compared to SARS-CoV and related SARS-like coronaviruses. bioRxiv.

50. Zhou Y, et al. (2015) Protease inhibitors targeting coronavirus and filovirus entry. Antiviral Res 116:76-84.

51. Zhou T, et al. (2020) Cryo-EM Structures of SARS-CoV-2 Spike without and with ACE2 Reveal a pH-Dependent Switch to Mediate Endosomal Positioning of Receptor-Binding Domains. Cell host \& microbe 28(6):867-879 e865.

52. Helenius A, Kartenbeck J, Simons K, \& Fries E (1980) On the entry of Semliki forest virus into BHK-21 cells. The Journal of cell biology 84(2):404-420.

53. Mazelier M, et al. (2016) Uukuniemi Virus as a Tick-Borne Virus Model. J Virol 90(15):67846798.

54. Lozach PY, et al. (2011) DC-SIGN as a receptor for phleboviruses. Cell host \& microbe $10(1): 75-88$.

55. Persson R \& Pettersson RF (1991) Formation and intracellular transport of a heterodimeric viral spike protein complex. The Journal of cell biology 112(2):257-266.

56. Meier R, et al. (2014) Genome-wide small interfering RNA screens reveal VAMP3 as a novel host factor required for Uukuniemi virus late penetration. J Virol 88(15):8565-8578.

57. Leger P, et al. (2020) NSs amyloid formation is associated with the virulence of Rift Valley fever virus in mice. Nat Commun 11(1):3281.

58. Woelfl F, et al. (2020) Novel Toscana Virus Reverse Genetics System Establishes NSs as an Antagonist of Type I Interferon Responses. Viruses 12(4). 


\section{$738 \quad$ Figures}

739 Fig. 1. Quantification of SARS-CoV-2 infection. ( $A$ and $B$ ) Cells were lysed and analyzed by

740 SDS-PAGE and western blotting under non-reducing conditions (A) and reducing conditions (B).

741 A549*, ACE2-expressing A549 cells. (C) Vero and Caco-2 cells were infected with SARS-CoV-2

742 at a $\mathrm{MOI}$ of 0.5 and 0.1 , respectively, for $8 \mathrm{~h}$. Infected cells were then permeabilized and

743 immunostained against the intracellular SARS-CoV-2 nucleoprotein (NP, red). Nuclei were stained

744 with DAPI (blue) before imaging by fluorescence wide-field microscopy. (D) Vero and Caco-2 cells

745 were exposed to SARS-CoV-2 at a $\mathrm{MOI}$ of 0.003 and 0.3 , respectively, and harvested $16 \mathrm{~h}$ later.

746 After fixation and permeabilization, infected cells were stained with the primary mAb against NP.

747 Infection was analyzed by flow cytometry. SSC-A, side scatter, area. $(E)$ Infection of Vero and

748 Caco-2 cells was monitored over $24 \mathrm{~h}$ using the flow cytometry-based assay used for the

749 experiment shown in panel D. Infection is given as the total fluorescence associated with the NP

750 protein-positive cells. MFI, mean of fluorescence intensity. ( $F$ ) SARS-CoV-2 mRNA levels were

751 quantified by qRT-PCR in both Vero and Caco-2 cells infected at MOls of 0.5 and 0.1 , respectively,

752 for up to $24 \mathrm{~h}$. (G) Supernatants from infected cells were collected during the time course in $\mathrm{F}$ and

753 assessed for the production of new infectious viral particles using a TCID50 assay on naïve Vero

754 cells.

Fig. 2. SARS-CoV-2 makes a differential use of host cell proteases for infectious

penetration. ( $A$ and $B$ ) Cells were pre-treated at indicated concentrations of aprotinin $(A)$ and

SB412515 (B), which are inhibitors of TMPRSS2 and cathepsin L, respectively. Infection with SARS-CoV-2 (MOI of 0.9) was achieved in the continuous presence of drug. Infected cells were quantified by flow cytometry as described in Fig. $1 D$, and data normalized to samples where inhibitors had been omitted. ( $C$ and $D$ ) SARS-CoV-2 particles (MOI of 0.9 ) were bound to A549* and Vero cells (C) or Calu-3 and Caco-2 cells (D) on ice for $90 \mathrm{~min}$, and subsequently, warmed rapidly to $37^{\circ} \mathrm{C}$ to allow infectious penetration. $10 \mu \mathrm{M}$ of SB412515 (C) or $30 \mu \mathrm{M}$ of aprotinin (D) 
763

764

765

766

767

768

769

770

771

772

773

774

775

776

777

778

779

780

781

782

783

784

785

786

787

were added at different times post warming to block further proteolytic activation. Infection was analyzed by flow cytometry, and data were normalized to samples where protease inhibitors had been omitted.

Fig. 3. SARS-CoV-2 infection depends on endosomal acidification. ( $A$ to $D$ ) Cells were pretreated with endosomal-pH interfering drugs at indicated concentrations and subsequently infected with SARS-CoV-2 in the continuous presence of drug, namely $\mathrm{NH}_{4} \mathrm{Cl}(\mathrm{A})$, chloroquine (B), Bafilomycin A1 (C), Concanamycin B (D). Infected cells were quantified by flow cytometry as described in Fig. $1 D$, and data normalized to samples where inhibitors had been omitted. $(E)$ Binding of SARS-CoV-2 to cells was synchronized on ice for $90 \mathrm{~min}$. Subsequently, cells were rapidly shifted to $37^{\circ} \mathrm{C}$ to allow penetration. $\mathrm{NH}_{4} \mathrm{Cl}\left(50 \mathrm{mM}\right.$ for $\mathrm{A} 549^{*}$ and Vero cells, and $75 \mathrm{mM}$ for Calu-3 and Caco-2 cells) was added at indicated times to neutralize endosomal $\mathrm{pH}$ and block the acid-dependent step of SARS-CoV-2 infectious penetration. Infected cells were analyzed by flow cytometry, and data normalized to samples where $\mathrm{NH}_{4} \mathrm{Cl}$ had been omitted. $(F)$ Same than in (E) but using Concanamycin $\mathrm{B}(50 \mathrm{nM})$ instead $\mathrm{NH}_{4} \mathrm{Cl}$. Uukuniemi virus (UUKV) was used to control the efficiency of Concanamycin B to neutralize endosomal pH in Caco-2 cells.

Fig. 4. SARS-CoV-2 relies on late endosomal maturation for infection. $(A)$ EGFP-Rab7a wildtype (wt), Q79L (constitutively active mutant), and T22N (dominant-negative mutant) were transiently expressed in Vero cells. The cells were then infected with SARS-CoV-2 at a MOI 0.003. Using flow cytometry, cell populations were selected for levels of EGFP-Rab7a expression in roughly one-log increments, and infected cells were quantified within each population 8 hpi. Data were normalized to infection in cell populations with the lowest EGFP-Rab7a intensity. Unpaired t-test with Welch's correction was applied. ${ }^{*}, \mathrm{p}<0.05 ;{ }^{* *}, \mathrm{p}<0.01$. RU, relative unit. ( $B$ and $C$ ) Cells were pre-treated with colcemid $(B)$ and MG-132 $(C)$ at indicated concentrations and subsequently infected with SARS-CoV-2 in the continuous presence of inhibitors. Infection was analyzed by flow cytometry, and data were normalized to samples where inhibitors had been 
omitted. Unpaired t-test with Welch's correction was applied. * $p<0.05 ;{ }^{* \star}, p<0.01 ;{ }^{* \star *}, p<$

added to cells at indicated times to block further late endosomal maturation. Infection was

analyzed by flow cytometry, and data were normalized to samples where MG-132 had been

omitted. $(E)$ As in the panel B but using Caco-2 cells instead Vero cells. ( $F$ ) Same as C, except

for Calu-3 and Caco-2 cells. (G) The timing of the MG-132-sensitive step during SARS-CoV-2

795 infectious entry into Calu-3 and Caco-2 cells was assayed as detailed in D but using $60 \mu \mathrm{M}$ of 796 MG-132.

Fig. 5. Acidification is not sufficient to trigger SARS-CoV-2 membrane fusion. $(A)$ SARS-

CoV-2 and (B) Semliki forest virus (SFV) particles were pre-treated at indicated $\mathrm{pH}$ for $10 \mathrm{~min}$ at $37^{\circ} \mathrm{C}$. Viruses were subsequently neutralized with buffers at $\mathrm{pH} \sim 7.4$ and allowed to infect Caco-

flow cytometry. Data are normalized to samples pretreated with buffers at $\mathrm{pH} \sim 7.4$. (C) Confluent monolayers of Vero cells were infected with SARS-CoV-2 at a MOI $\sim 0.003$ for $24 \mathrm{~h}$ prior to treatment with buffers at indicated $\mathrm{pH}$ for 5 min at $37^{\circ} \mathrm{C}$. Plasma membrane was stained $1 \mathrm{~h}$ posttreatment with CellMask Deep Red (red). After fixation, nuclei were stained with Hoechst (blue). White stars indicate syncytia. $(D)$ Images of microscope fields $(32<\mathrm{n}<44)$ obtained in $(C)$ were quantified. Fusion index is given as $f=1-$ [(number of cells in a field after fusion]/[number of nuclei)]. Unpaired t-test with Welch's correction was applied. ns, non-significant.

Fig. 6. Proteolytic processing triggers SARS-CoV-2 membrane fusion. ( $A$ ) SARS-CoV-2 (MOI 
$8135 \mathrm{~min}$ at $37^{\circ} \mathrm{C}$. Plasma membrane was stained with CellMask Deep Red (red) $1 \mathrm{~h}$ after

814 trypsinization. After fixation, nuclei were stained with Hoechst (blue), and cells imaged by wide-

815 field fluorescence microscopy. White stars indicate syncytia. $(C)$ Images of microscope fields $(n=$

81639 , no protease, $n=63$, trypsin, and $n=54$, furin) obtained in (B) were quantified. Fusion index

817 is calculated as in Fig. 5D. Unpaired t-tests with Welch's correction was applied. ${ }^{* *}, \mathrm{p}<0.01$.

818 Fig. 7. SARS-CoV-2 no longer requires endosomal acidification after proteolytic

819 processing. $(A)$ Confluent monolayers of Vero cells were infected with SARS-CoV-2 at a MOI

$820 \sim 0.003$ for $24 \mathrm{~h}$ and then subjected to trypsin treatment for $5 \mathrm{~min}$ at $37^{\circ} \mathrm{C}$. The cells were allowed

821 to recover for $1 \mathrm{~h}$ at $37^{\circ} \mathrm{C}$, and subsequently, exposed to buffers at indicated $\mathrm{pH}$ for $5 \mathrm{~min}$ at $37^{\circ} \mathrm{C}$.

822 Cell-cell fusion was determined as described in Fig. $6 B$ and $6 C . \mathrm{n}>28$ microscope fields were

823 analyzed, and unpaired t-test with Welch's correction was applied. ns, non-significant. (B) Shows

824 the increase in cell-cell fusion after trypsin treatment according to $\mathrm{pH}$. The fusion is given as the

825 ratio between the values obtained for trypsin-treated samples and those obtained for untreated

826 samples. (C) SARS-CoV-2 particles (MOI of 1.2) were first subjected to trypsin treatment for 15

827 min at $37^{\circ} \mathrm{C}$ followed by exposition to buffers at indicated $\mathrm{pH}$ for $10 \mathrm{~min}$ at $37^{\circ} \mathrm{C}$, and vice versa.

828 A549* and Vero cells were then infected and analyzed by flow cytometry as described in Fig. 1D.

829 (D) Trypsin-activated SARS-CoV-2 (MOI 0.003) was allowed to infect A549* and Vero cells in

830 the continuous presence of Bafilomycin A1. Infection was quantified by flow cytometry, and data

831 normalized to samples where the inhibitor had been omitted. ( $E$ and $F$ ) Binding of trypsin-activated

832 SARS-CoV-2 (MOI 0.003) to Vero (E) and A549* (F) was synchronized on ice for $90 \mathrm{~min}$.

833 Subsequently, cells were rapidly shifted to $37^{\circ} \mathrm{C}$ to allow penetration. $\mathrm{NH}_{4} \mathrm{Cl}(50 \mathrm{mM})$ was added

834 at indicated time to neutralize endosomal $\mathrm{pH}$ and block the acid-dependent step of SARS-CoV-2

835 infectious penetration. Infected cells were analyzed by flow cytometry, and data normalized to

836 samples where $\mathrm{NH}_{4} \mathrm{Cl}$ had been omitted.

837 Table 1. Half maximal inhibitory $\left(\mathrm{IC}_{50}\right)$ of inhibitors against SARS-CoV-2. 
A bioRxiv preprint doi: https://doi.org/10.1101/2020.12.22.423906; this veSon posted December 23, 2020. The copyright holder for this preprint (which was not certified by peer review) is the author/funder, who has granted bioRxiv a license to display the preprint in perpetuity. It is made available under aCC-BY-NC-ND 4.0 International license. CaCO-2

Vero A549* Calu-3 Caco-2

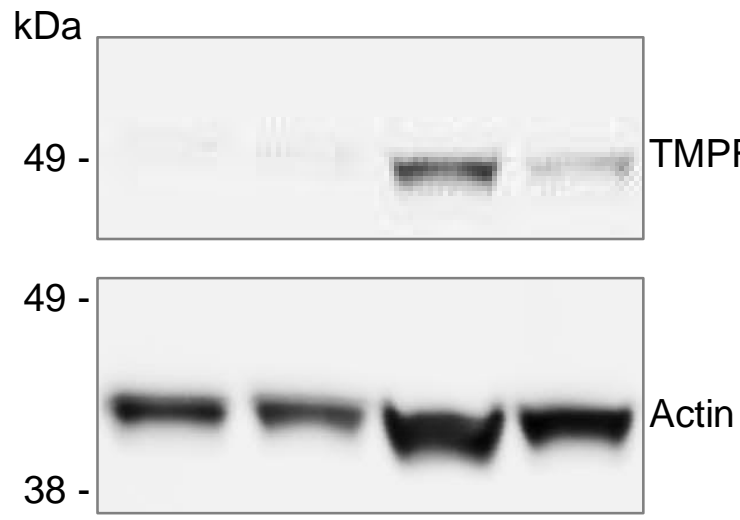

B

Vero A549* Caco-2 Calu-3

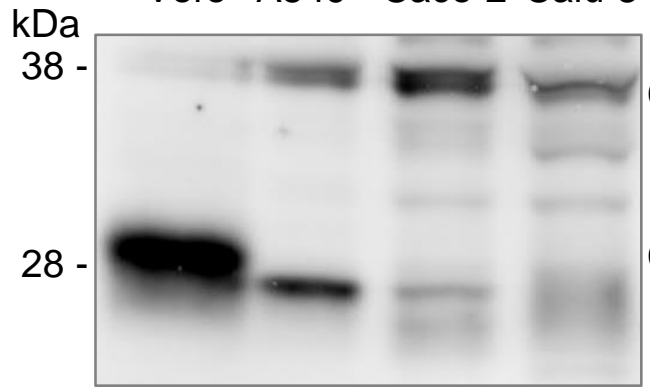

49

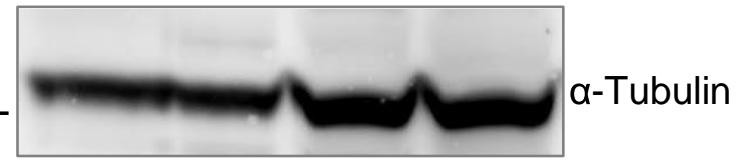

C

Caco-2

Vero
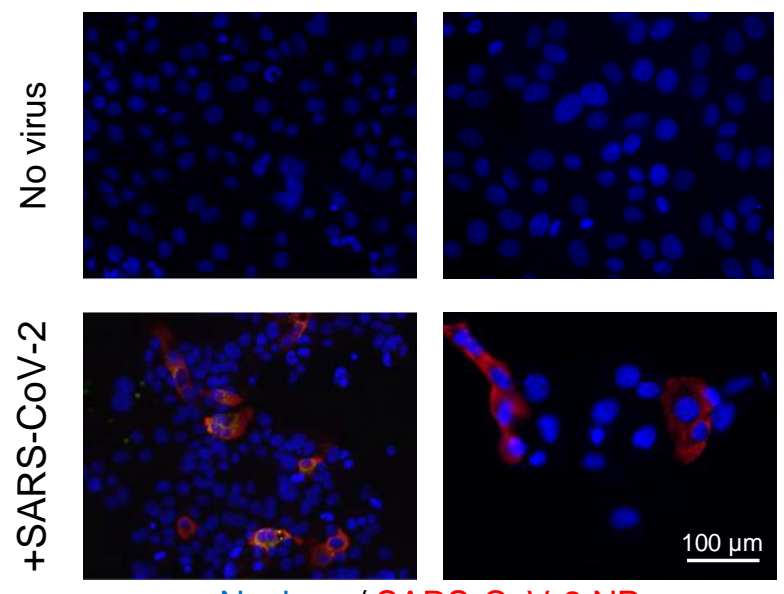

Nucleus / SARS-CoV-2 NP

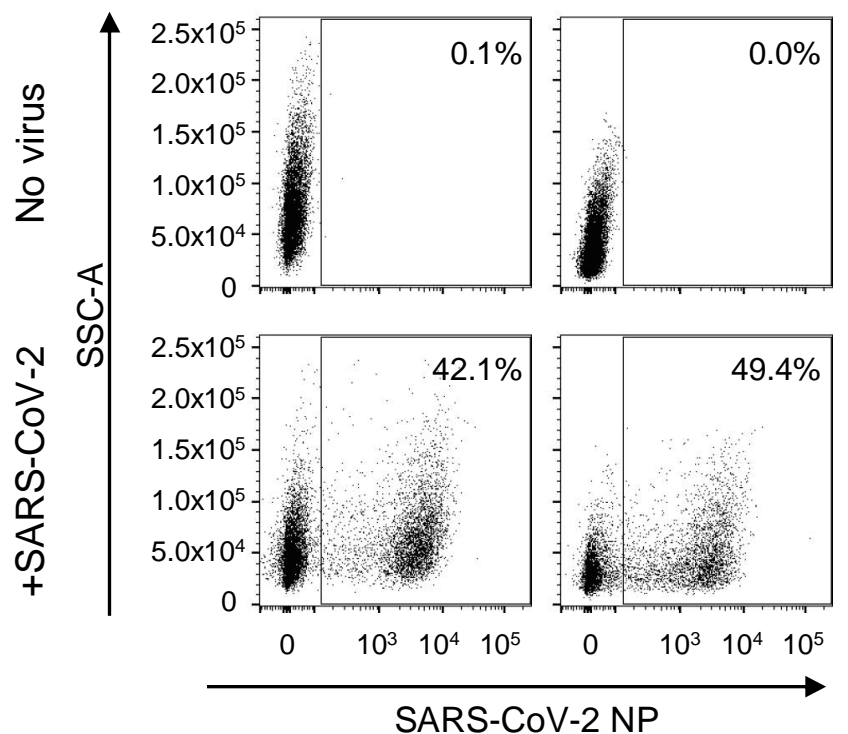

E
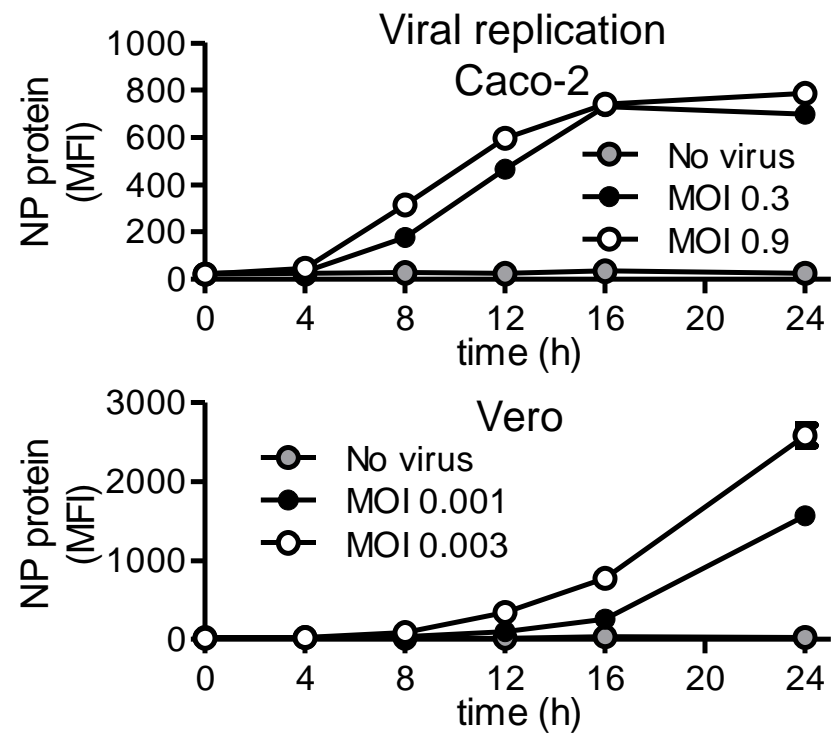

$\mathbf{F}$

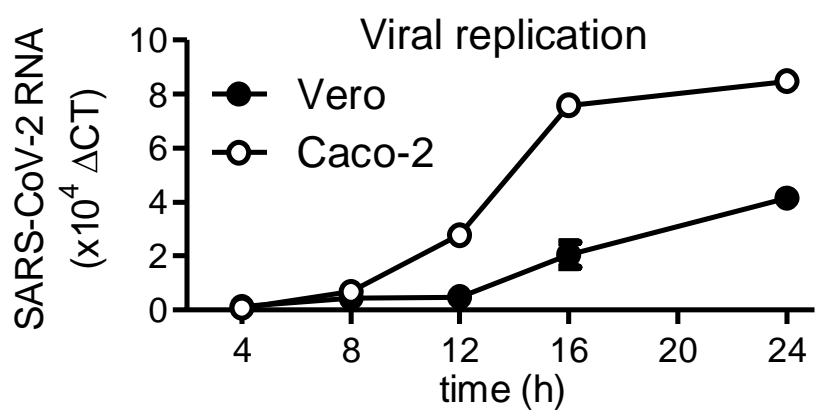

$\mathbf{G}$

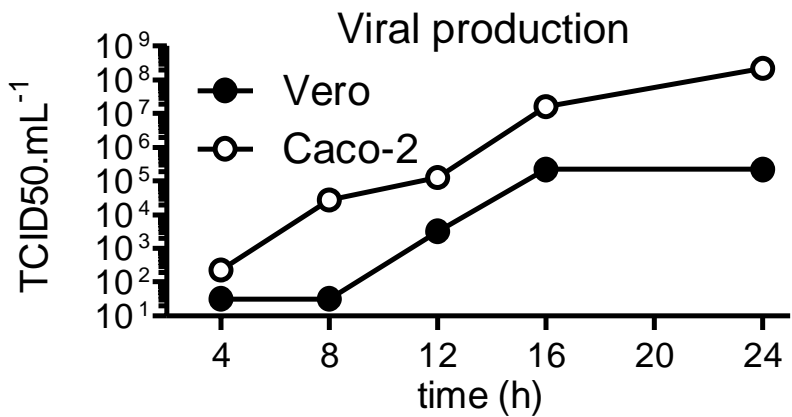


A

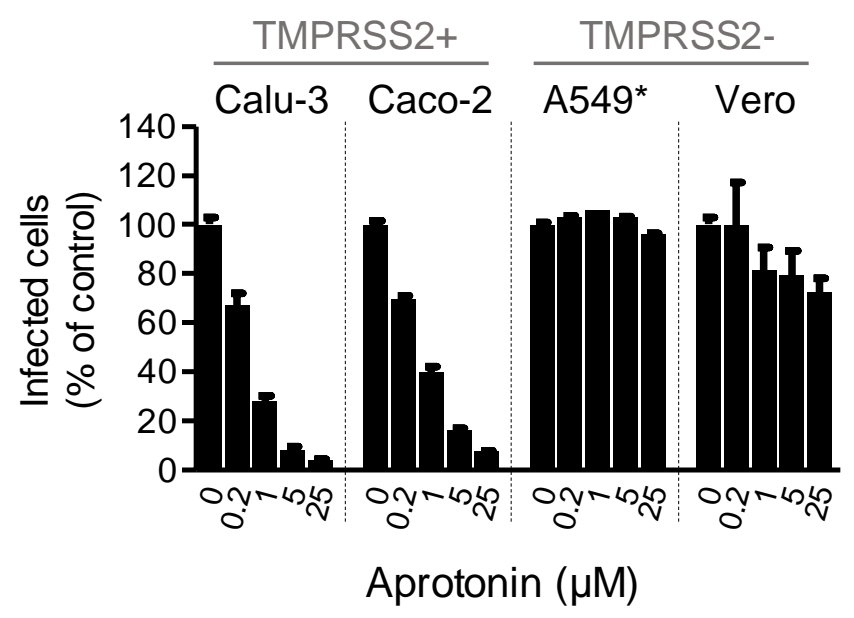

C

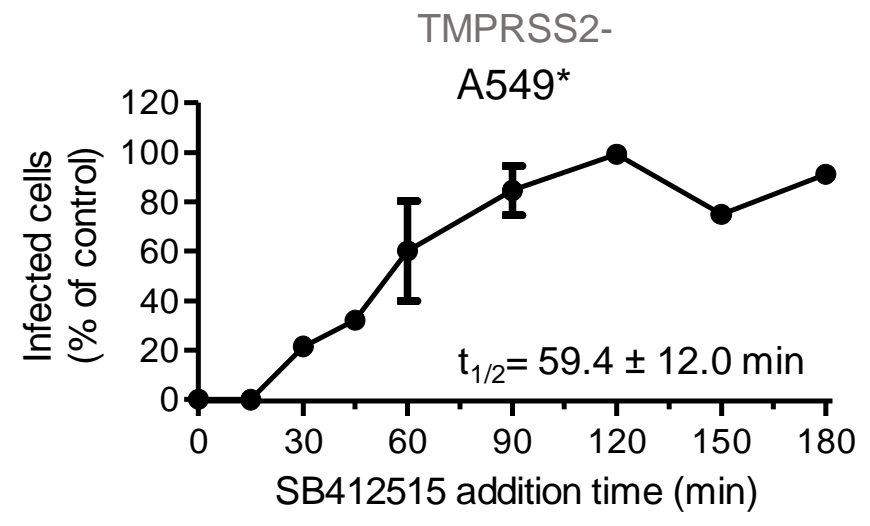

D

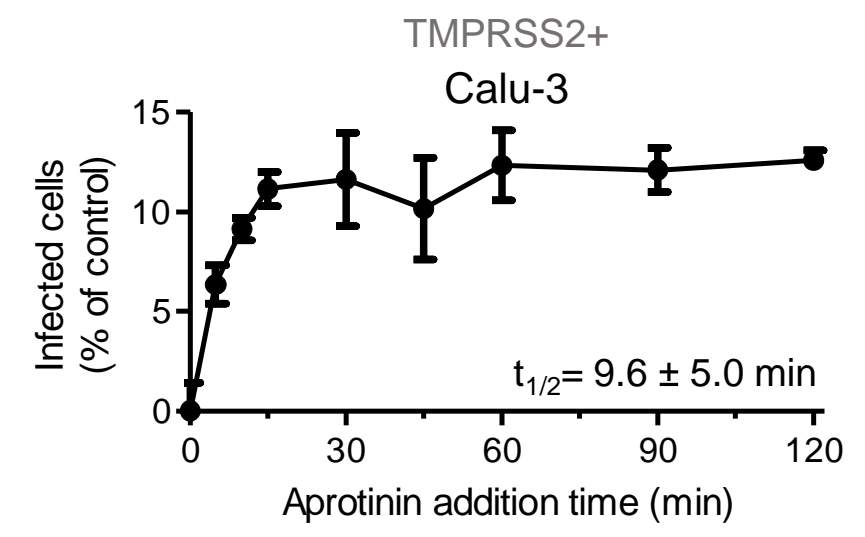

B
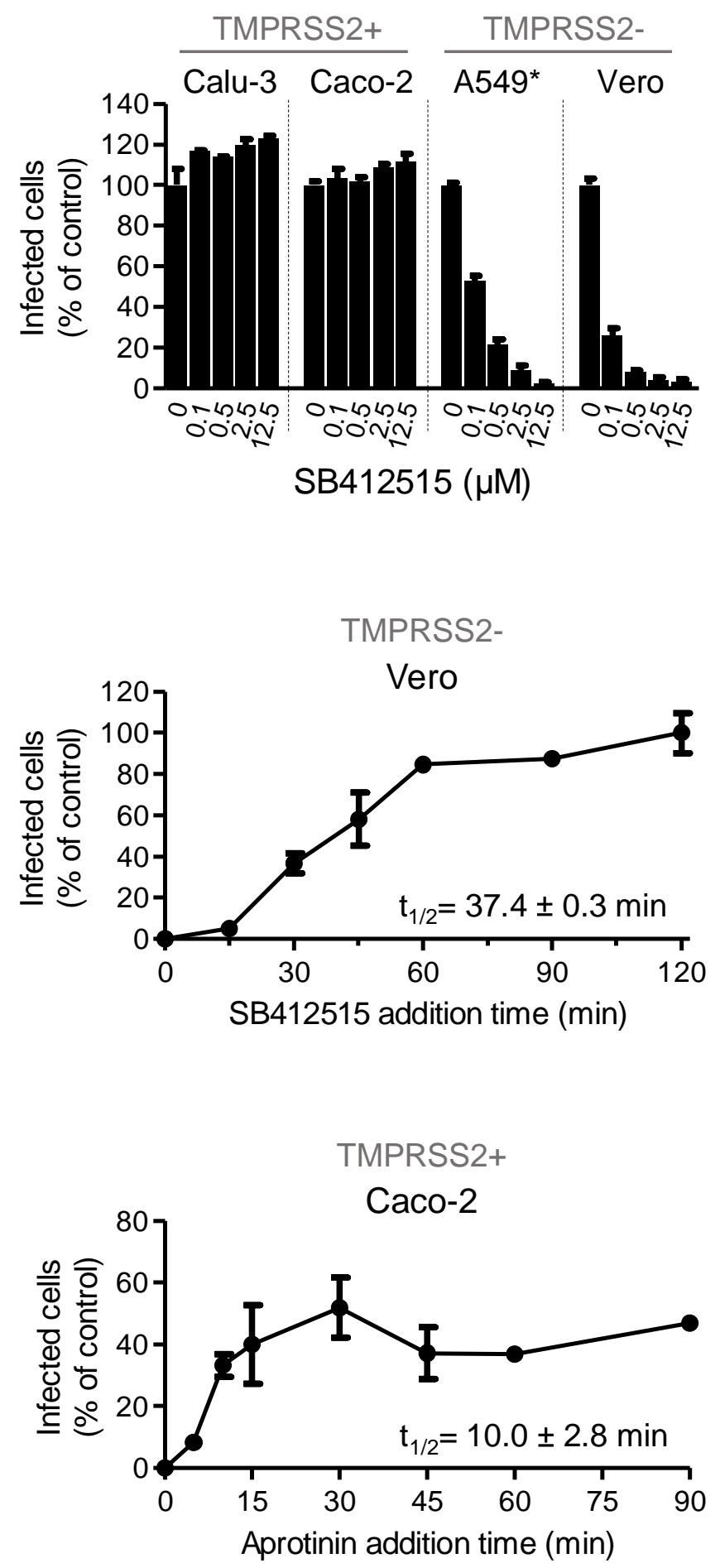

Fig. 2 
A

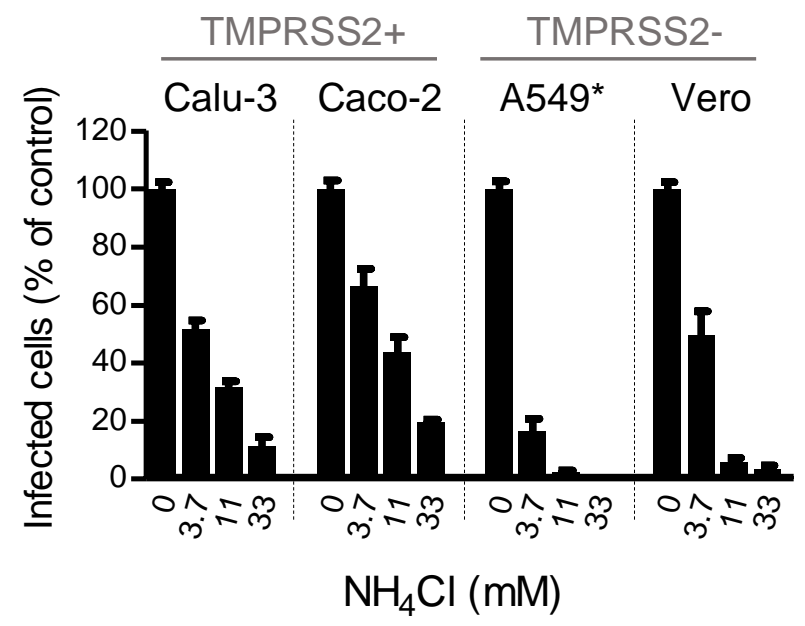

C

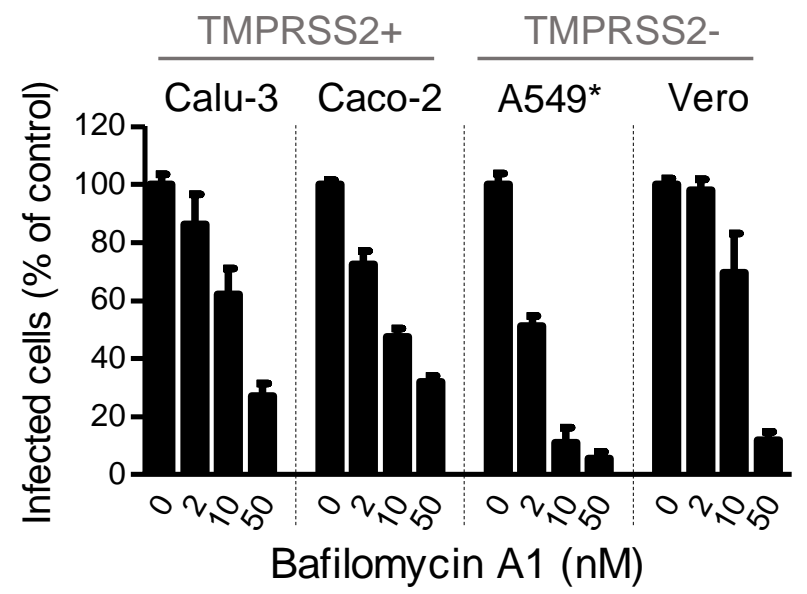

E

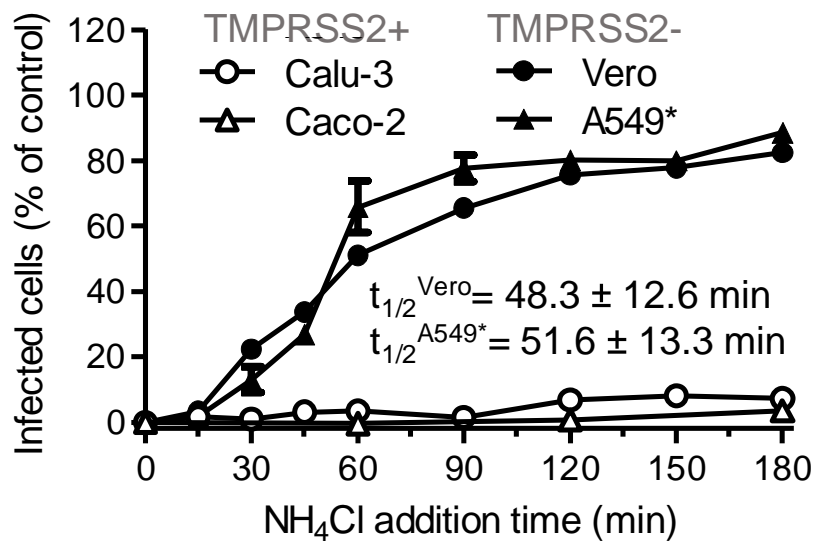

B

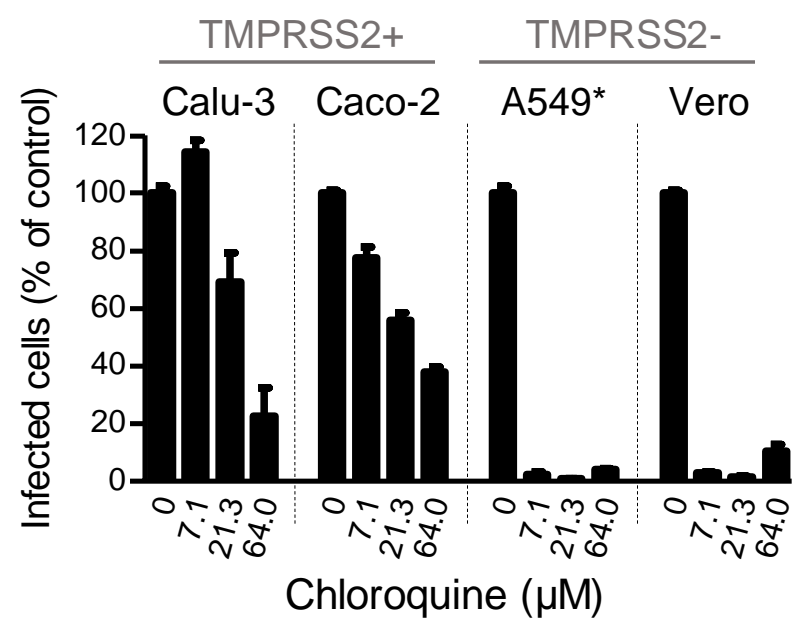

D

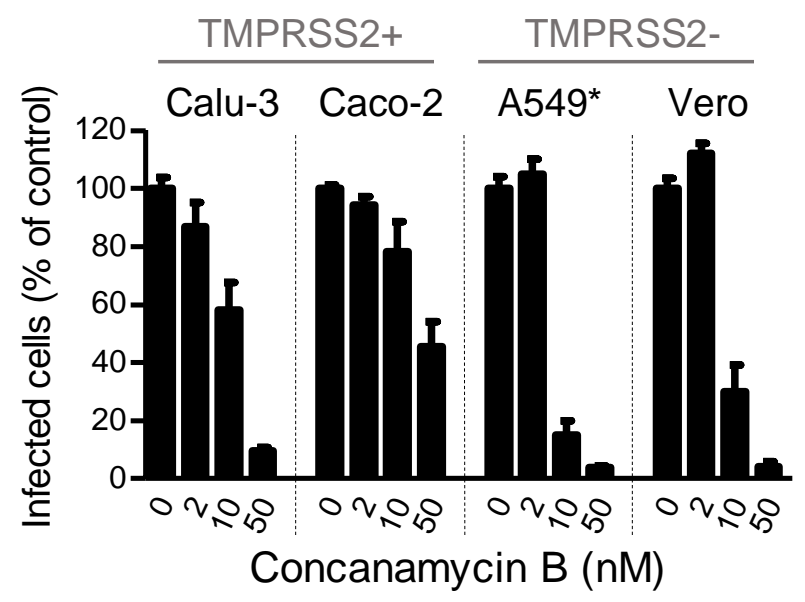

F

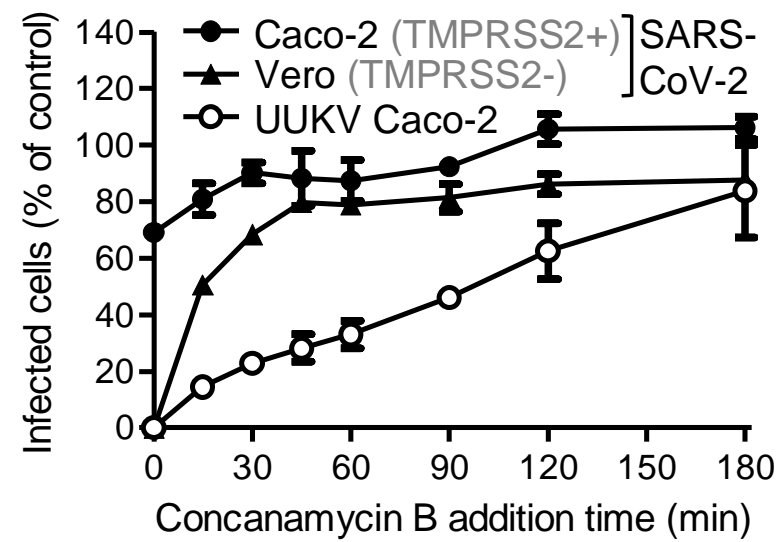


A

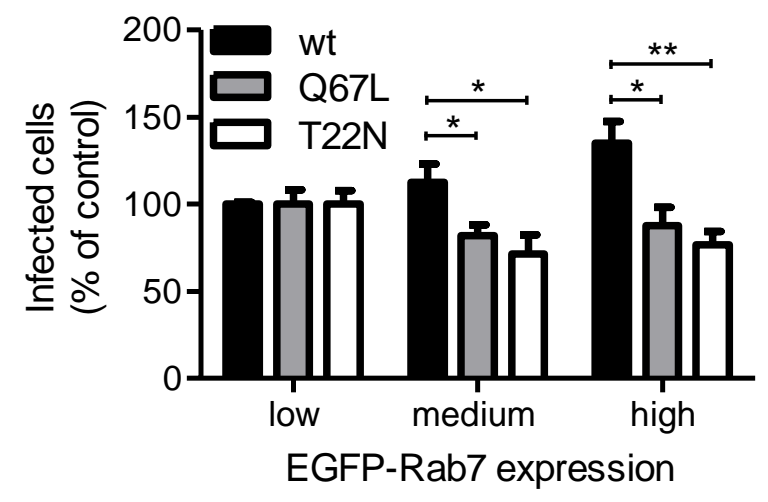

B

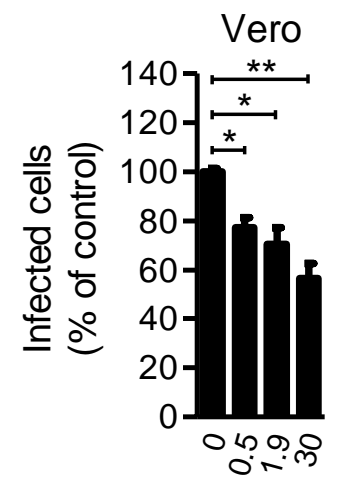

Colcemid $(\mu \mathrm{M})$
$\mathbf{E}$

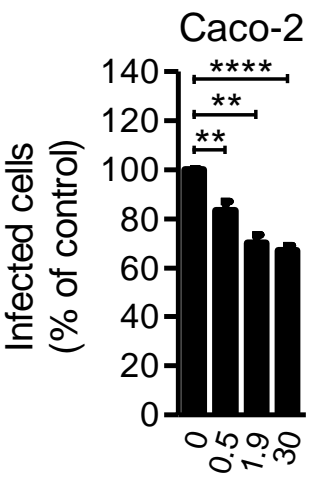

Colcemid $(\mu \mathrm{M})$
D

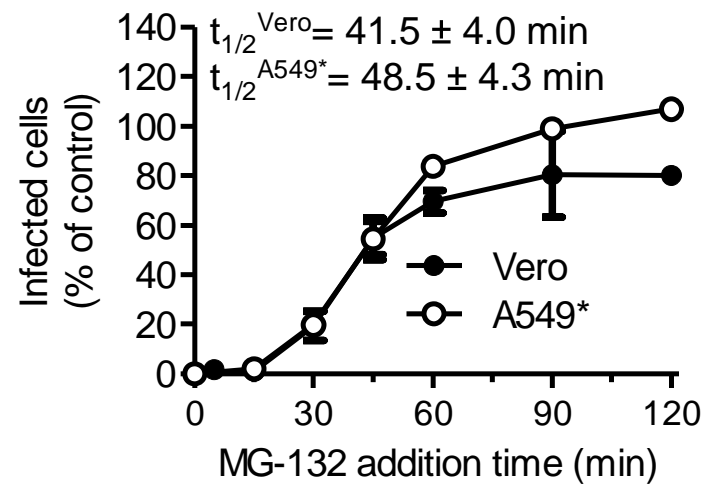

F

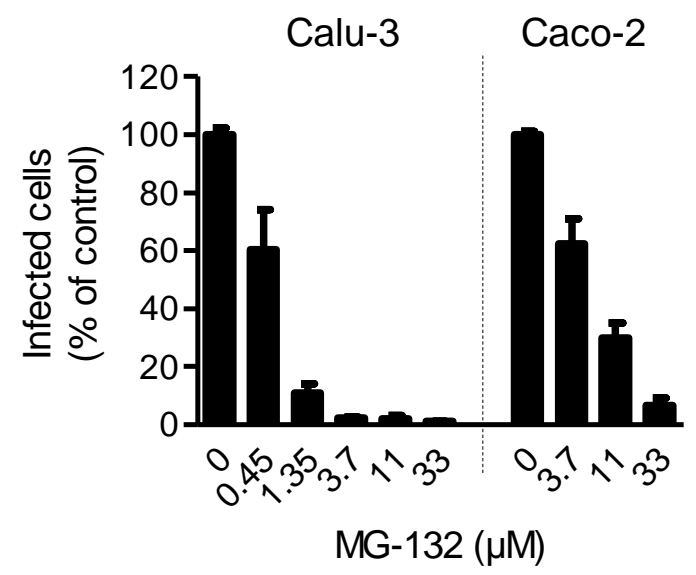

C

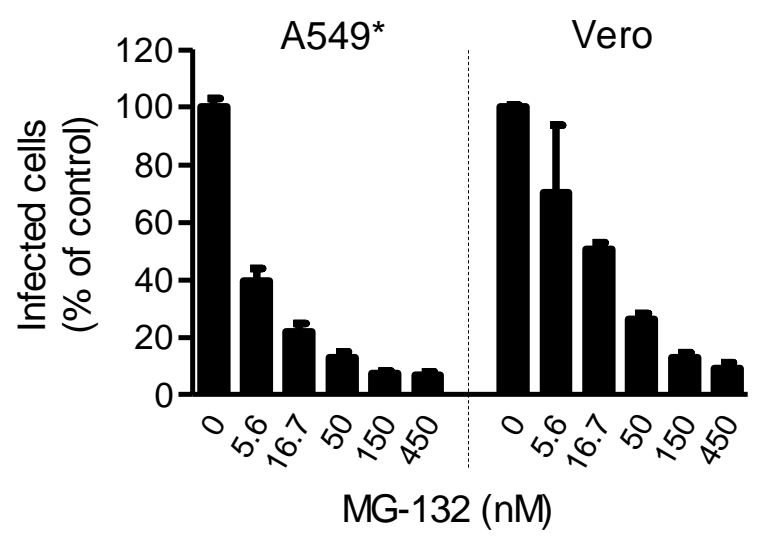

G

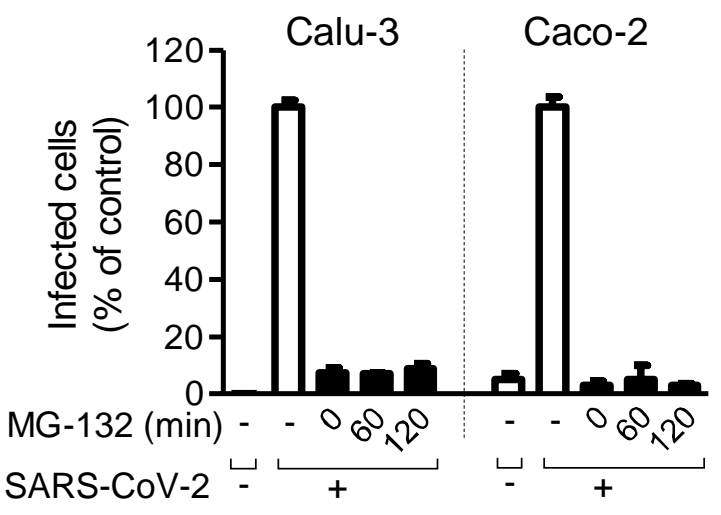


A

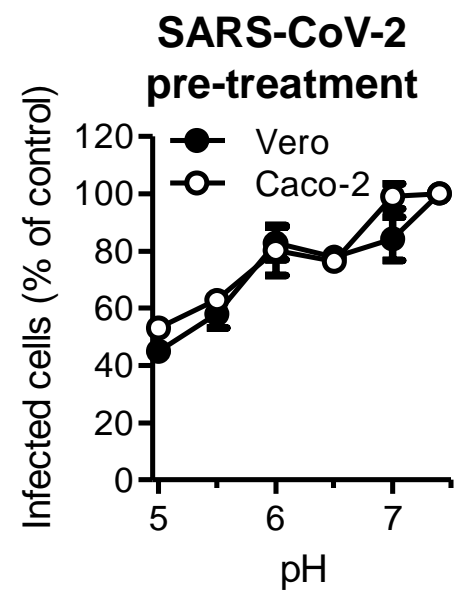

B

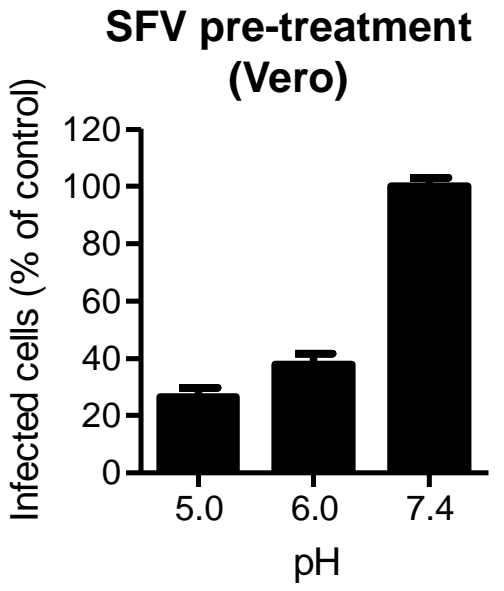

D

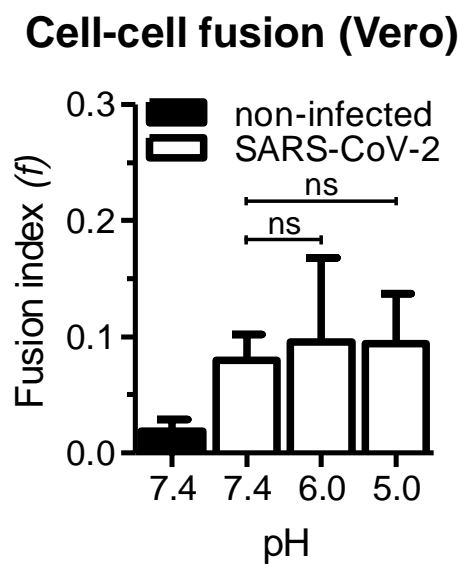

\section{C}

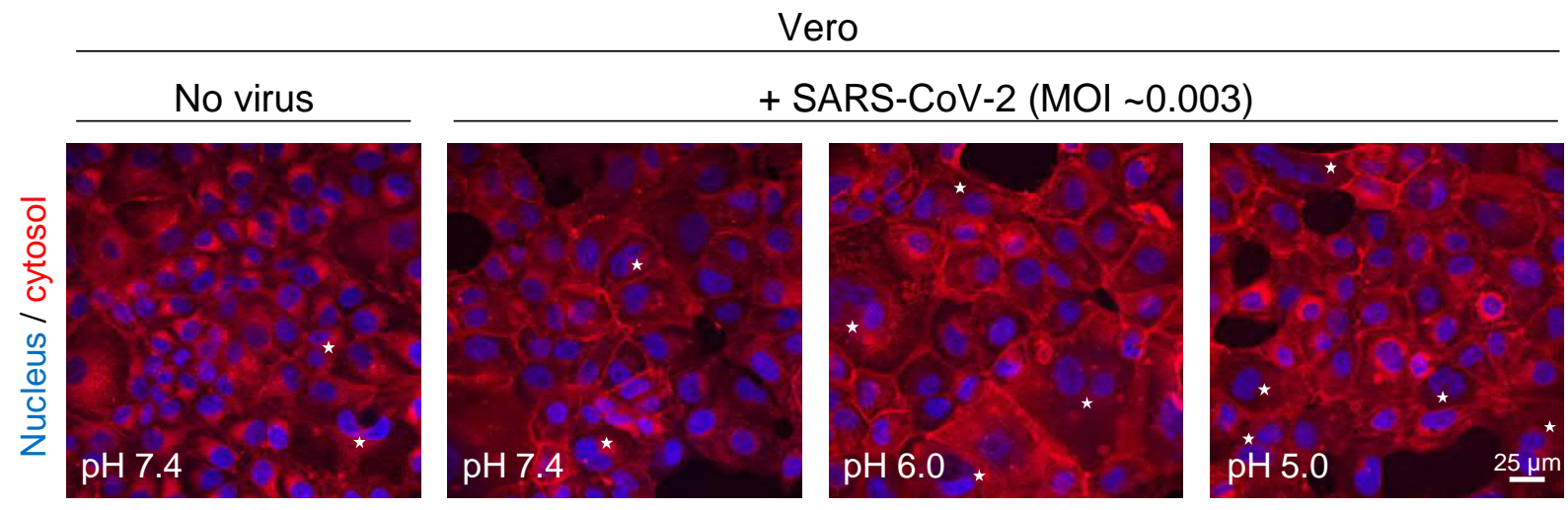

Fig. 5 
A

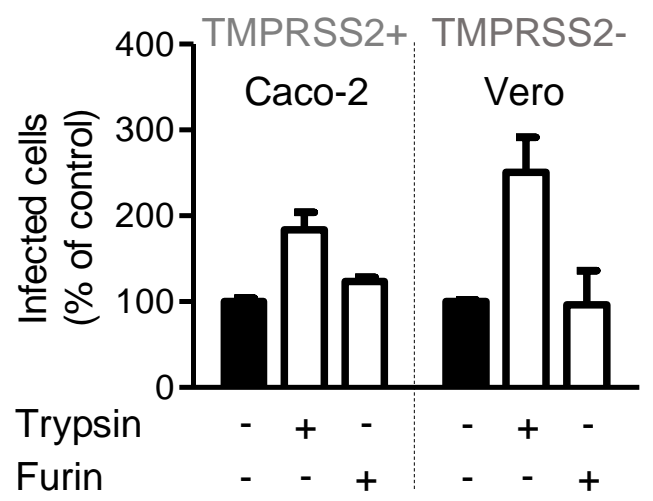

Cell-cell fusion (Vero)

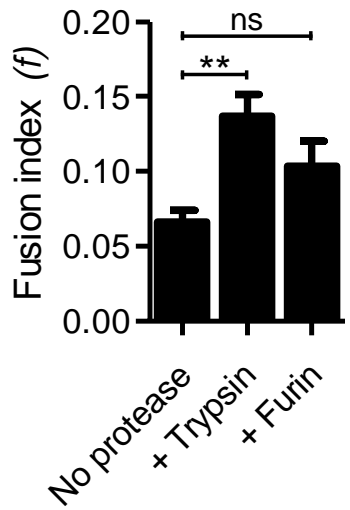

B

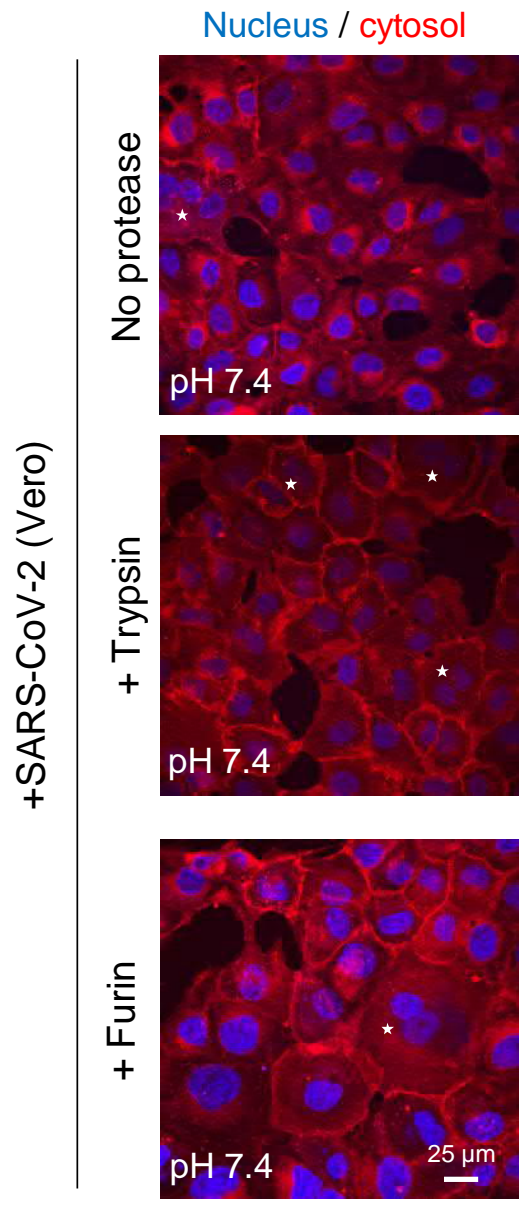


A

Cell-cell fusion (Vero)

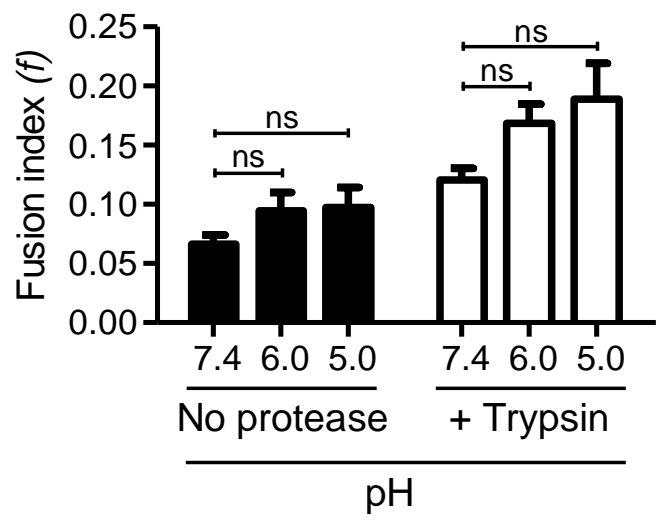

C

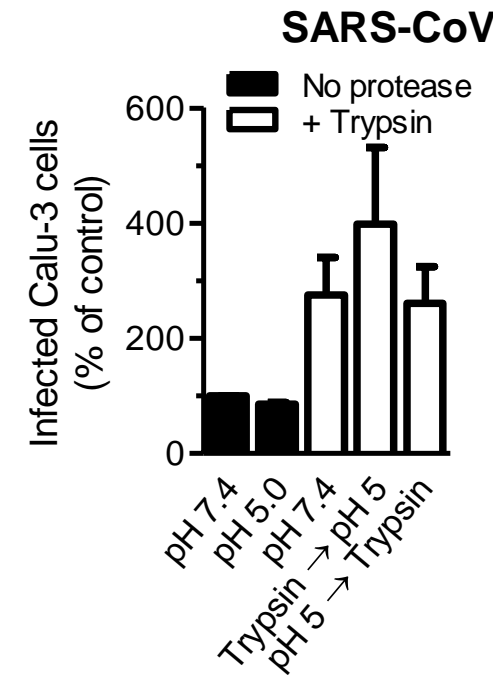

E

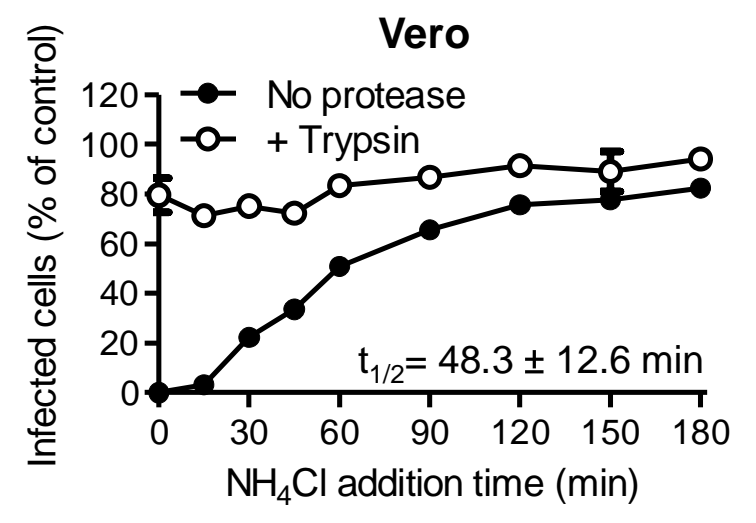

B

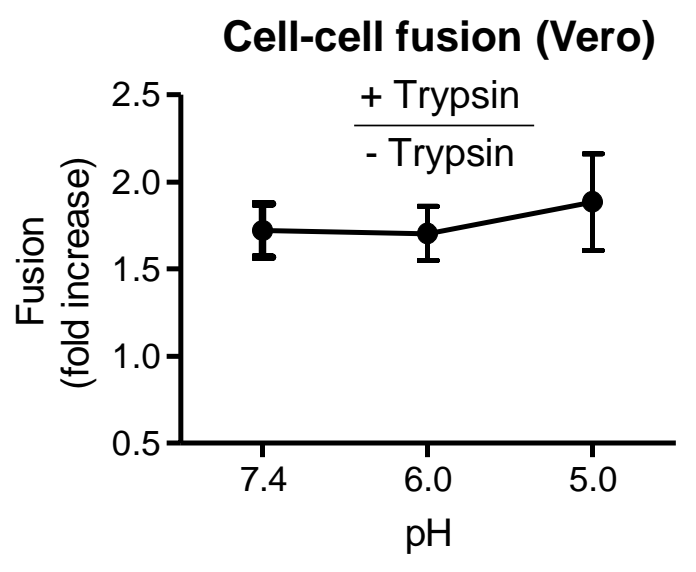

D

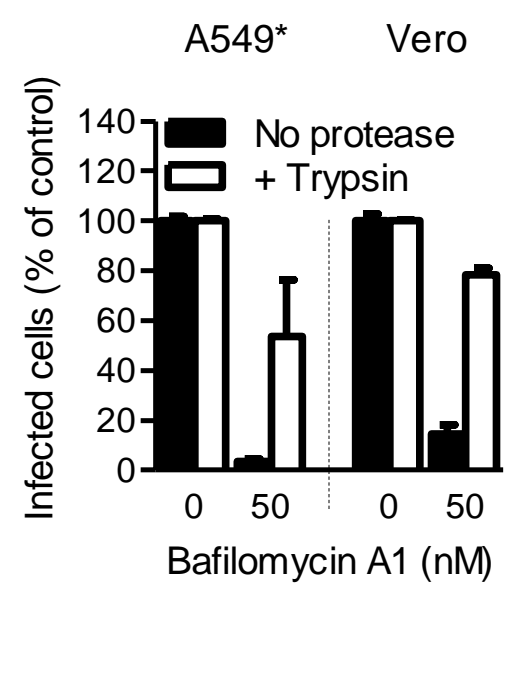

$\mathbf{F}$

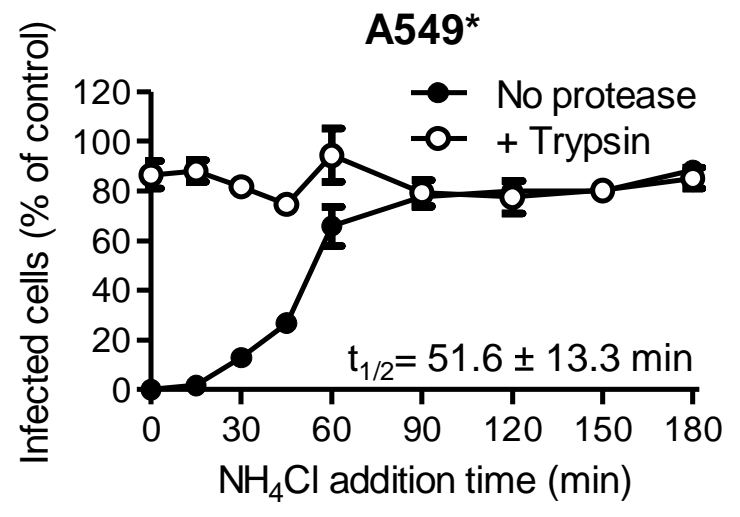




\begin{tabular}{|l|c|c|c|c|}
\hline & Calu-3 & Caco-2 & A549* & Vero \\
\hline Aprotonin & $0.4 \pm 0.1 \mu \mathrm{M}$ & $0.6 \pm 0.0 \mu \mathrm{M}$ & $\mathrm{x}$ & $\mathrm{x}$ \\
\hline $\mathrm{SB} 412515$ & $\mathrm{x}$ & $\mathrm{x}$ & $125.7 \pm 29.9 \mathrm{nM}$ & $36.9 \pm 10.9 \mathrm{nM}$ \\
\hline $\mathrm{NH}{ }_{4} \mathrm{Cl}$ & $4.4 \pm 0.9 \mathrm{mM}$ & $7.9 \pm 2.4 \mathrm{mM}$ & $2.2 \pm 0.1 \mathrm{mM}$ & $2.5 \pm 0.6 \mathrm{mM}$ \\
\hline Chloroquine & $50.1 \pm 24.4 \mu \mathrm{M}$ & $27.4 \pm 4.0 \mu \mathrm{M}$ & $0.3 \pm 0.0 \mu \mathrm{M}$ & $0.2 \pm 0.1 \mu \mathrm{M}$ \\
\hline Bafilomycin A1 & $16.3 \pm 6.6 \mathrm{nM}$ & $10.4 \pm 3.2 \mathrm{nM}$ & $2.0 \pm 0.6 \mathrm{nM}$ & $18.6 \pm 7.7 \mathrm{nM}$ \\
\hline Concanamycin B & $12.2 \pm 5.8 \mathrm{nM}$ & $50.3 \pm 30.4 \mathrm{nM}$ & $6.0 \pm 1.2 \mathrm{nM}$ & $8.6 \pm 2.2 \mathrm{nM}$ \\
\hline MG-132 & $0.7 \pm 0.2 \mu \mathrm{M}$ & $5.2 \pm 2.1 \mu \mathrm{M}$ & $4.4 \pm 1.4 \mathrm{nM}$ & $16.4 \pm 5.6 \mathrm{nM}$ \\
\hline
\end{tabular}

